\title{
On the Structure and Kinematics of an Algerian Eddy in the Southwestern Mediterranean Sea
}

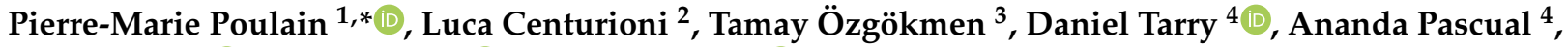 \\ Simon Ruiz ${ }^{4}$ (D), Elena Mauri ${ }^{5}$ (D), Milena Menna ${ }^{5}$ (D) and Giulio Notarstefano ${ }^{5}$
}

1 NATO Science and Technology Organization, Center for Maritime Research and Experimentation, 19126 La Spezia, Italy

2 Scripps Institution of Oceanography, University of California San Diego, La Jolla, CA 92093, USA; lcenturioni@ucsd.edu

3 Rosenstiel School of Marine and Atmospheric Science, University of Miami, Miami, FL 33149, USA; tozgokmen@rsmas.miami.edu

4 Mediterranean Institute for Advanced Studies, Spanish National Research Council and University of Balearic Islands, 07190 Esorles, Spain; drtarry@imedea.uib-csic.es (D.T.); ananda.pascual@imedea.uib-csic.es (A.P.); simon.ruiz@imedea.uib-csic.es (S.R.)

5 National Institute of Oceanography and Experimental Geophysics, Oceanography Section, 34010 Sgonico, Italy; emauri@inogs.it (E.M.); mmenna@inogs.it (M.M.); gnostarstefano@inogs.it (G.N.)

* Correspondence: pierre-marie.poulain@cmre.nato.int

check for

updates

Citation: Poulain, P.-M.; Centurioni, L.; Özgökmen, T.; Tarry, D.; Pascual, A.; Ruiz, S.; Mauri, E.; Menna, M.;

Notarstefano, G. On the Structure and Kinematics of an Algerian Eddy in the Southwestern Mediterranean Sea. Remote Sens. 2021, 13, 3039. https:// doi.org/10.3390/rs13153039

Academic Editor: Vladimir N. Kudryavtsev

Received: 3 July 2021

Accepted: 29 July 2021

Published: 3 August 2021

Publisher's Note: MDPI stays neutral with regard to jurisdictional claims in published maps and institutional affiliations.

Copyright: (c) 2021 by the authors. Licensee MDPI, Basel, Switzerland. This article is an open access article distributed under the terms and conditions of the Creative Commons Attribution (CC BY) license (https:// creativecommons.org/licenses/by/ $4.0 /)$.

\begin{abstract}
An Algerian Eddy, anticyclonic vortex generated by the instability of the Algerian Current in the southwestern Mediterranean Sea, is studied using data provided by drifters (surface currents), Argo floats (temperature and salinity profiles), environmental satellites (absolute dynamic topography maps and ocean color images) and operational oceanography products. The eddy was generated in May 2018 and lasted as an isolated vortex until November 2018. Its morphology and kinematics are described in June-July 2018 when drifters were trapped in its core. During that period, the eddy was slowly moving to the NE ( $\sim 2 \mathrm{~km} /$ day), with an overall diameter of about $200 \mathrm{~km}$ (slowly growing with time) and maximal surface swirl velocity of $\sim 50 \mathrm{~cm} / \mathrm{s}$ at a radius of $\sim 50 \mathrm{~km}$. Geostrophic currents derived from satellite altimetry data compare well with low-pass filtered drifter velocities, with only a slight overestimation, which is expected as its maximum vorticity corresponds to a small Rossby number of $\sim 0.6$. Satellite ocean color images and some drifters show that the eddy has an elliptical spiral structure. The looping tracks of the drifters trapped in the eddy were analyzed using two statistical methods: least-squares ellipse fitting and wavelet ridge analysis, revealing a typical eccentricity of about 0.5 , a wide range of inclination and a rotation period between 3 and 10 days. Clusters of drifters on the northeastern limb of the eddy were also considered to estimate divergence and vorticity. The results indicate convergence (divergence) and downwelling (upwelling) at scales of 20-50 km near the northeastern (northwestern) edge of the eddy, in agreement with the quasi-geostrophic theory. Vertically, the eddy extends mostly down to $250 \mathrm{~m}$ depth, with a warm, low-salinity and low-density signature and with geostrophic currents near $50 \mathrm{~cm} / \mathrm{s}$ in the top layer (down to $\sim 80 \mathrm{~m}$ ) reducing to less than $10 \mathrm{~cm} / \mathrm{s}$ near $250 \mathrm{~m}$. Near the surface, colder water is advected into it.
\end{abstract}

Keywords: southwestern Mediterranean Sea; Algerian eddy; satellite altimetry; drifters and floats

\section{Introduction}

Vortices are ubiquitous circulation features of the world's oceans. Their size varies from $\sim 100 \mathrm{~km}$ (mesoscale) to $\sim 10 \mathrm{~km}$ (submesoscale). They can be permanently located in specific areas (in this case they are often referred to as gyres) or can move, evolve in time, interact with each other, etc. (in this case they are generally called eddies). Mesoscale eddies and gyres are easily detected in sea surface height data provided by satellite altimeters. Submesocale and mesoscale vortices are also well identified in the tracks of Lagrangian 
drifters and floats at the sea surface and in the ocean interior, respectively. If drifters or floats are trapped in vortices, they can provide unique measurements about their structure and kinematics [1-4], although trapping and the persistence in the eddies can generally be due to several complex factors [5], including the fact that the instruments do not follow exactly the currents.

In this paper, the data of numerous drifters and some floats are used to study an anticyclonic eddy in the southwestern Mediterranean Sea. None of the Lagrangian instruments were purposefully deployed in the eddy. They were deployed elsewhere and were subsequently trapped in its core or felt the influence of its outside edge for a few weeks. The Lagrangian data are complemented by operational oceanography products mainly based on satellite remote sensing data.

The vortex circulation feature considered in this work was located off the North African coast in the southwestern Mediterranean Sea (Figure 1), an area dominated by the Algerian Current $(\mathrm{AC})$. The $\mathrm{AC}$ is a strong eastward coastal or slope current transporting waters of Atlantic origin (entering through Gibraltar Strait and known as the Atlantic Water-AW) in the upper water column. The AW is the water with the lowest salinity in the whole Mediterranean Sea, with salinity values ranging from 36 to 37 [6]. East of $\sim 0^{\circ} \mathrm{E}$, the $\mathrm{AC}$ generates meanders and develops strong and long-lived anticyclonic Algerian Eddies (AEs) via mixed barotropic-baroclinic instability processes [6-10]. These eddies have a diameter of $100 \mathrm{~km}$, move with a typical speed of a few $\mathrm{km} /$ day and dominate the dynamics and the local ecosystem of most of the southwestern Mediterranean [11]. They detach from the AC and propagate slowly to the NE between longitudes 0 and $4^{\circ} \mathrm{E}$. Once they are detached, they can move either to the NE or the NW. East of $6^{\circ} \mathrm{E}$ they are blocked by the topography of the Sardinian Passage (near $9^{\circ} \mathrm{E}$ ) and mostly move northward in the central western Mediterranean Sea west of Sardinia [12] before dissipating.

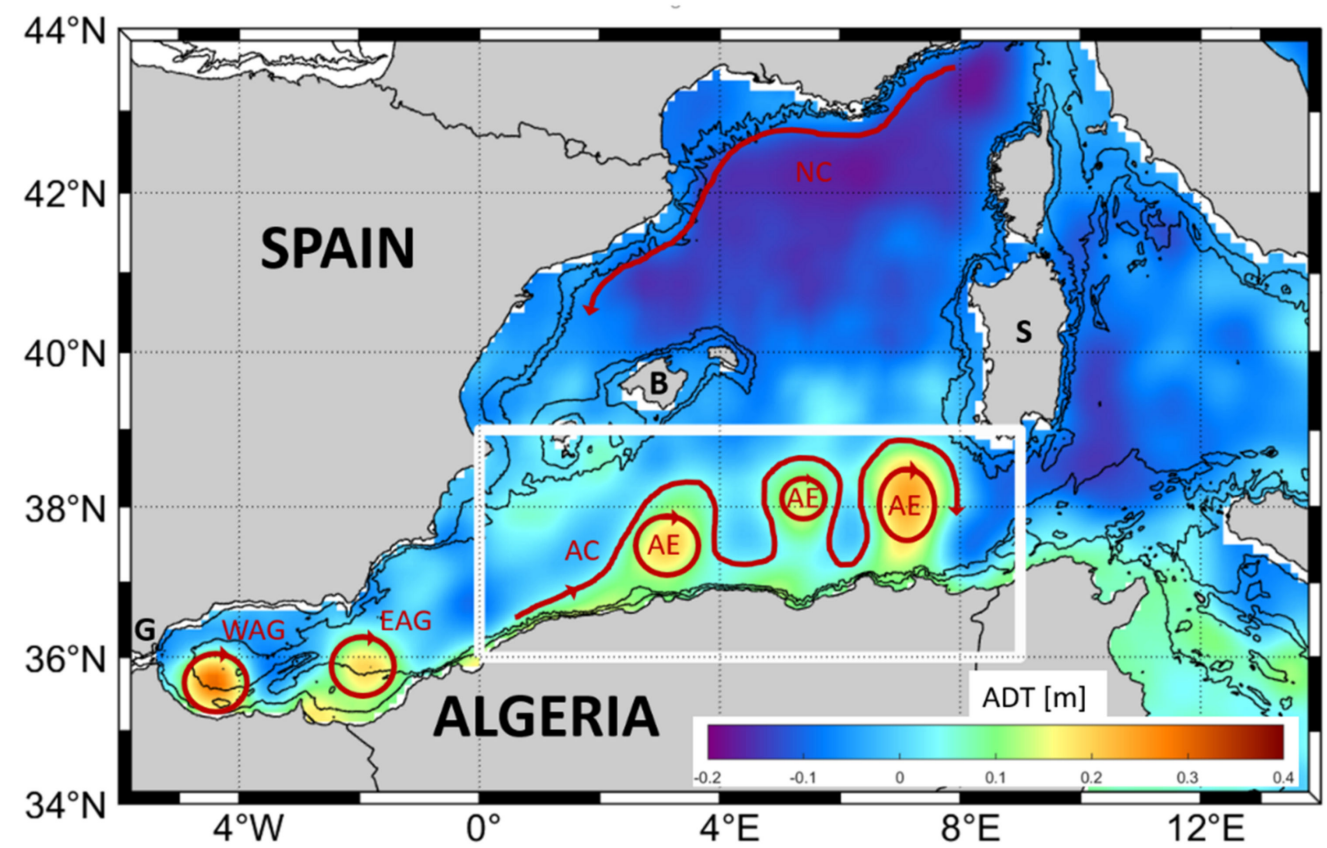

Figure 1. Western Mediterranean Sea with color-coded mean absolute dynamic topography (ADT) for June 2018. The $200 \mathrm{~m}$ and $1000 \mathrm{~m}$ isobaths are shown with black curves. The main area of interest is depicted by a white rectangle. The main currents and gyres are sketched in red (Western Alboran Gyre-WAG, Eastern Alboran Gyre-EAG, Algerian Current-AC, Algerian Eddies-AE and Northern Current-NC).The Balearic (B) and Sardinia (S) Islands, and the Strait of Gibraltar (G) are indicated.

The goal of this paper is to study one specific AE during stratified conditions (from spring to fall 2018) using Lagrangian data and operational products, with particular 
focus on its morphology and kinematics. Details about the Lagrangian instruments and observations, and about the operational products (satellite altimetry data, chlorophyll concentration maps, vertical velocity from Omega equation) are given in Section 2. Results are presented in Section 3. First, satellite altimetry products are used to describe the AE evolution from its detachment of the AC in mid-May 2018 until its dissipation in November 2018. Second, the structure and kinematics of the AE are studied using combined satellite altimetry data and in situ observations by drifters and profiling floats in June-July 2018. Vertical velocity is estimated using the drifter cluster method and compared to the values derived with the quasi-geostrophic (QG) Omega equation. Discussion and conclusions can be found in Sections 4 and 5, respectively.

\section{Data and Methods}

\subsection{Lagrangian Instruments and Data}

The drifter data used in this work were downloaded from the OGS Mediterranean drifter database [13]. For the southwestern Mediterranean Sea in 2018, they mainly consist of drifters released in the Alboran Sea during the "Coherent Lagrangian Pathways from the Surface Ocean to Interior (CALYPSO)" pilot experiment [14,15].

The data originate from four types of drifters: the SVP, DWSD, CODE and CARTHE designs. The Surface Velocity Program (SVP) drifter is the standard drifter of the Global Drifter Program [16-18]. It consists of a spherical surface buoy tethered to a holey sock drogue that allows the track of the horizontal motion of water at a nominal depth of $15 \mathrm{~m}$. Below the surface buoy, a tether strain gauge measures the tension of the buoydrogue connection to monitor the drogue presence and a thermistor measures sea surface temperature. Measurements of the water-following capabilities of the SVP have shown that when the drogue is attached it follows the water near $15 \mathrm{~m}$ depth to within $1 \mathrm{~cm} / \mathrm{s}$ in $10 \mathrm{~m} / \mathrm{s}$ winds [19]. Without the drogue the difference between the $15 \mathrm{~m}$ current and the drifter velocity can be as much as $1 \%$ of the wind speed [20].

The Directional Wave Spectrum Drifter (DWSD) is essentially a SVP for which the drogue was replaced by a small $(\sim 50 \mathrm{~cm})$ stabilizing chain [21]. It is equipped with a GPS engine paired with software algorithms for onboard computation of the directional wave spectrum of the surface waves.

The Coastal Ocean Dynamics Experiment (CODE, [22]) drifter measures the currents within the top meter of the water column (nominal depth of $0.8 \mathrm{~m}$ ). It is composed of a slender, vertical, $1 \mathrm{~m}$-long negatively buoyant tube with four drag-producing vanes extending radially from the tube over its entire length and four small spherical surface floats attached to the upper extremities of the vanes to provide buoyancy [23]. The CODE drifters follow the currents with an accuracy of about $3 \mathrm{~cm} / \mathrm{s}$, even under strong wind conditions [24]. The wind-induced slippage was estimated to be $0.1 \%$ of the local wind speed.

Consortium for Advanced Research on Transport of Hydrocarbon in the Environment (CARTHE) drifters were developed to be compact, easy to transport and assemble, and 85\% biodegradable [25] so that very large deployments can be attempted in the ocean while being eco-friendly. They are composed of a torus float and a small drogue to measure the surface currents within $60 \mathrm{~cm}$ of the sea surface. Direct wind-induced slip amounts to less than $0.5 \%$ of the wind speed.

If compared to drogued SVP drifters, CARTHE and CODE drifters move essentially downwind by $0.5-1 \%$ of the wind speed [26]. The differences between the CARTHECODE and SVP currents are due to direct wind-driven slippage, rectification by surface waves, Stokes drift and the shear of mainly ageostrophic currents between the surface and $15 \mathrm{~m}$ depth.

All drifters transmitted their GPS data (and other ancillary data) via either Iridium (SVP) or GlobalStar (CODE and CARTHE) satellites.

Only the drifter GPS data were considered for this work. In the OGS database, they were processed with standard methods for editing, low-pass filtering (36 h) and 
interpolation [13,27]. Velocities were estimated by finite differencing of successive positions. The position and velocity data are available at $6 \mathrm{~h}$ intervals. For the SVP drifters, the tether strain gauge data confirmed that for the period considered the drogue was attached to the surface buoy. For the CARTHE units, it was assumed that the drogue remained attached.

Profiles of temperature and salinity from three Argo floats located near the AE under study in June and July 2018 were downloaded from the Argo Global Data Assembly Centre (GDAC) [28]. They correspond to Arvor floats of the Argo-Italy program (World Meteorological Organization-WMO numbers 3901849 and 6901836) and the Monitoring the Oceans and Climate Change with Argo (MOCCA) European project (WMO 3901907). Profiles are available every 5 days with the maximum depth alternating between 700 and $2000 \mathrm{~m}$. The vertical resolution is $2 \mathrm{~m}$ (in 0-100 m), $10 \mathrm{~m}$ (in 100-700 m) and $25 \mathrm{~m}$ (in 700-2000 m).

The Argo float data used in this work have been validated using the Delayed Mode Quality Control (DMQC) technique. The strategy adopted for DMQC is described in [29-33]. After DMQC, the accuracies of the Argo temperature and salinity measurements are $0.05^{\circ} \mathrm{C}$ and 0.01, respectively. However, for two floats (WMO 6901836 and 3901907) a salinity drift with time is evident and accuracy in salinity can be of the order of 0.1 . For the water mass analyses presented in this paper, this degraded accuracy is nevertheless acceptable.

\subsection{Operational Products}

The daily absolute dynamic topography (ADT) and corresponding absolute geostrophic velocities (AGV) on a $0.125^{\circ}$ Mercator projection grid were downloaded from the Copernicus Marine Environment Monitoring Service (CMEMS; DATASET-DUACS-REP-MEDSEAMERGED-ALLSAT-PHY-L4, product user manual CMEMS-SL-QUID_008-032-062) for the southwestern Mediterranean Sea between May and October 2018. The ADT was obtained by adding the sea level anomaly to the 20-year synthetic mean over the 1993-2012 period [34].

Satellite images of surface chlorophyll concentration were downloaded from CMEMS (dataset-oc-med-chl-multi_cci-13-chl_1km_daily) for the Mediterranean Sea in June and July 2018. The absolute values of chlorophyll concentration are not considered in this work; chlorophyll is considered as a quasi-passive tracer of the surface water masses and only used qualitatively to better describe the surface currents. Due to cloud coverage, only a few clear images are available in the study area for the period considered.

Data of wind speed and direction $10 \mathrm{~m}$ above sea level were downloaded from the Copernicus Climate Data Store for June and July 2018 in the southwestern Mediterranean. They correspond to the fifth generation European Centre for Medium-Range Weather Forecasts (ECMWF) reanalysis (ERA5) for the global climate and weather. These data were used to estimate the wind-related slip of the CARTHE and CODE drifters.

In this study we also used the CMEMS OMEGA3D product [35] obtained by applying a diabatic QG diagnostic model to the data-driven ARMOR3D reconstructions as well as ERA Interim fluxes. The ARMOR3D product is a multivariate global ocean 3D state estimation based on the synergy of temperature and salinity fields [36,37]. It combines remote sensing observations (sea level anomaly_SLA, and sea surface temperature-SST) with in situ vertical profiles of temperature and salinity via a multiple linear regression method and optimal interpolation. Vertical velocities are retrieved in the upper $1500 \mathrm{~m}$ at 75 unevenly spaced layers at $0.25^{\circ}$ nominal resolution and successively used to compute the horizontal ageostrophic components. OMEGA3D fields are distributed by CMEMS within the product MULTIOBS_GLO_PHY_W_3D_REP_015_007.

\subsection{Methods}

Drifter track segments were overlaid on maps of ADT, AGV and chlorophyll concentration to describe the structure of the AE. Assuming circular rotation, tangential (or swirl) speeds were examined as a function of the distance from of the AE center, defined as the position of the local ADT maximum. Drifter and satellite-derived tangential speeds 
were compared using linear regression. Relaxing the circular assumption, two statistical methods, least-squares ellipse fitting and wavelet ridge analysis, were applied to the tracks of the drifters entrapped in the AE in order to estimate the parameters of the elliptical drifter paths. Details and an example can be found in the Appendix A.

The average relative vorticity inside the elliptical drifter track was estimated using Stokes' theorem [3]:

$$
<\zeta>=-\left(\frac{a}{b}+\frac{b}{a}\right) / P
$$

where $P$ is the period, and $a$ and $b$ are the semi-major and semi-minor axes, respectively. Vorticity was scaled by the local planetary vorticity, i.e., the inertial frequency $(f)$ at the latitude of the center of the ellipse.

The differential kinematic properties, in particular divergence and vorticity, were also estimated using the least-squares cluster method of [38] applied to 16 CARTHE and CODE drifters in and around the AE. The number of drifters, the length scale, and the aspect ratio are important for the accuracy in the velocity gradient estimate. Here we used 6 drifters per cluster as it is a good compromise between method accuracy and computational cost $[39,40]$. We defined the length scale of a cluster as the root mean squared distance of all pairs of drifters and only consider clusters with length scales between 20 and $50 \mathrm{~km}$. The cluster aspect ratio is the ratio of the minor and major eigenvalues of the position covariance matrix [41]. Isotropic clusters have an aspect ratio close to one, while for elongated clusters it is close to zero. Clusters with aspect ratio smaller than 0.1 were excluded.

\section{Results}

\subsection{Long-Term Evolution of the AE}

The surface circulation in the western Mediterranean Sea, from the mesoscale to the basin scale, is nicely described using ADT maps. For instance, the mean ADT map for June 2018 (Figure 1) reveals the following main circulation patterns: (1) a basin-wide cyclonic circulation including the $\mathrm{AC}$ to the south and the Northern Current to the north (corresponding to the broad minimum in ADT near $20 \mathrm{~cm}$ in the north and central parts of the basin); (2) strong anticyclonic vortices (ADT maxima near $30 \mathrm{~cm}$ ) off the African coast, comprising the Alboran gyres and the AEs; and (3) weaker cyclonic eddies generally embedded between the anticyclones.

We now focus on the southwest Mediterranean (also called Algerian basin and depicted with a white rectangle in Figure 1) and consider weekly ADT maps (Figures 2 and 3) to describe the spatial structure and temporal evolution of one specific AE located near $3^{\circ} 15^{\prime} \mathrm{E}$ and $37^{\circ} 30^{\prime} \mathrm{N}$ on the mean map of June 2018 . From mid-May to mid-June, this eddy was generated through the AC instability in the form of a meander growing in size (up to about $100 \mathrm{~km}$ in diameter) and moving slowly (about $2 \mathrm{~km} /$ day) towards the E. In mid-June, the eddy detached from the AC and became an independent vortex until the beginning of August. It expanded in size (up to $150 \mathrm{~km}$ in diameter) and in strength (with the ADT at its center reaching $40 \mathrm{~cm}$ ) and proceeded to the NE with a speed near $2 \mathrm{~km} /$ day. 


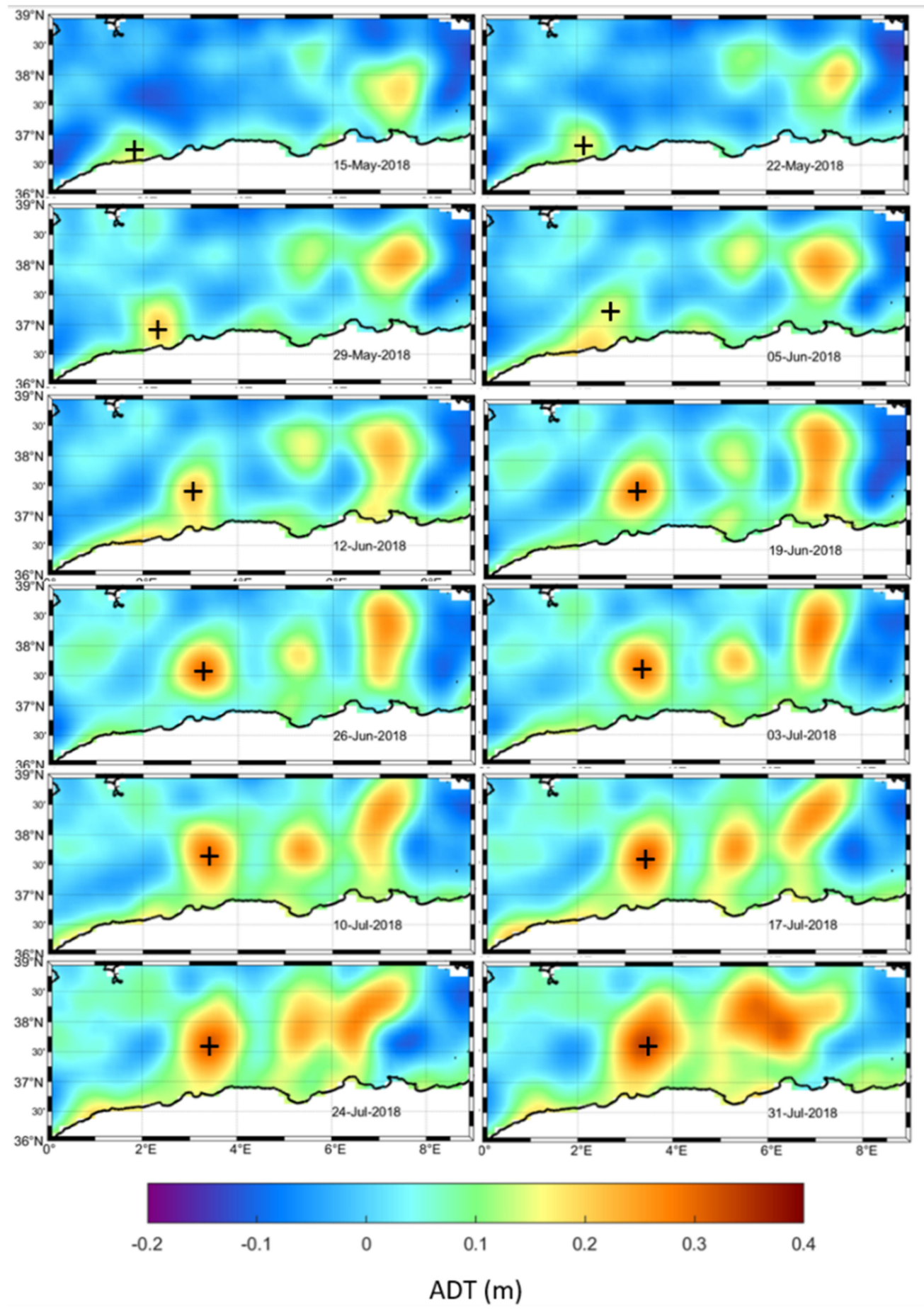

Figure 2. Weekly ADT (m) snapshot maps between mid-May and the end of July 2018 off the Algerian coast in the southwestern Mediterranean Sea. The center of the AE studied in this paper is shown with a plus sign. 


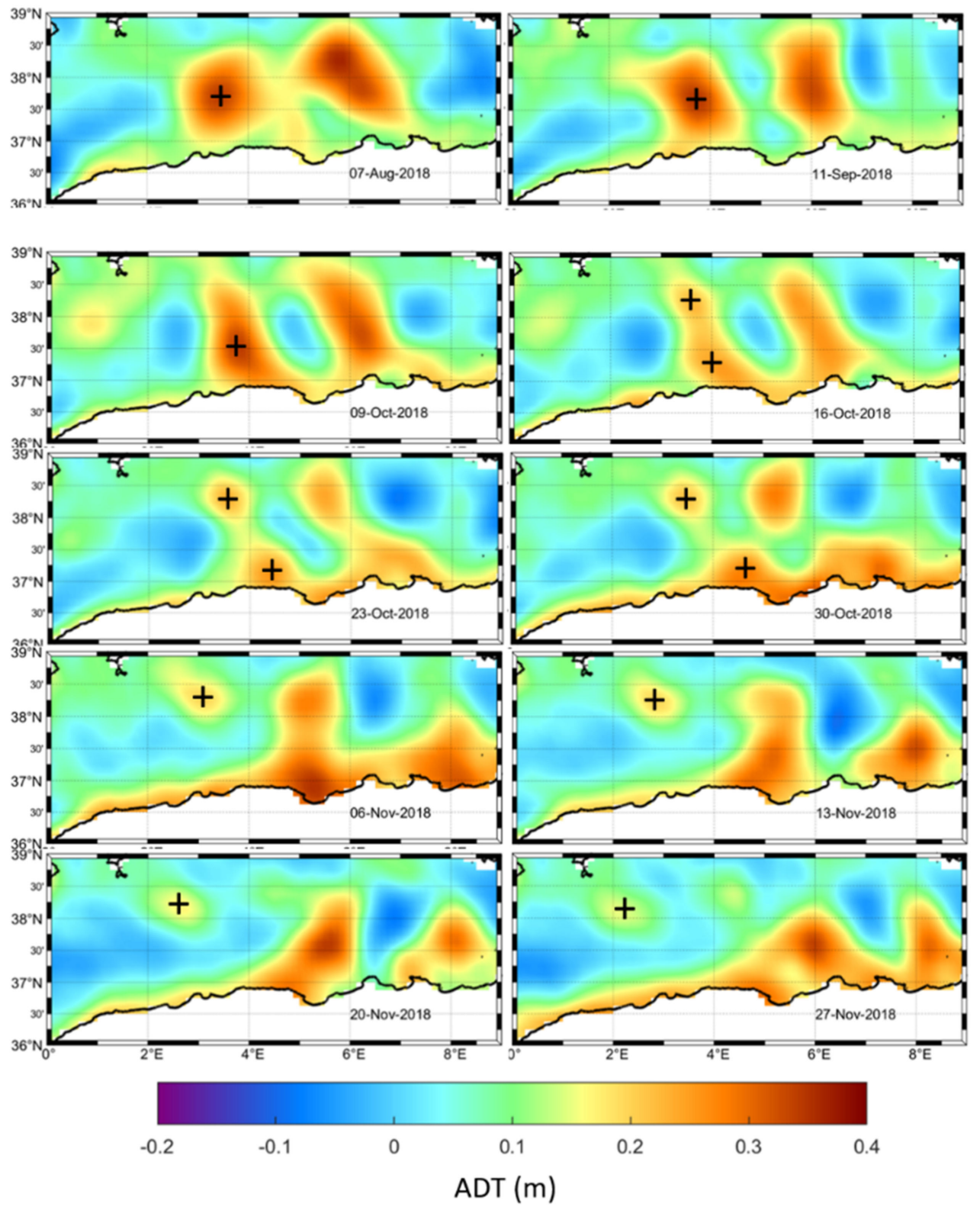

Figure 3. Same as in Figure 2 but for 7 August and 11 September 2018, and for the period OctoberNovember 2018.

In August and September 2018 (Figure 3, upper panels), the eddy interacted intermittently with another large AE located more to the E around $6^{\circ} \mathrm{E}$. During this period, its mean location did not change substantially. In October and November 2018, the eddy expanded to the NW and split into two parts, one remaining in proximity to the coast and continuing some eastward progression, and another detaching and moving to the NW while weakening (Figure 3). This part eventually dissipated in the open sea near $2^{\circ} \mathrm{E}$ south of the Balearic Islands.

\subsection{Evolution, Morphology and Kinematics of the AE in June-July 2018 \\ 3.2.1. Near-Surface Characteristics}

In June and July 2018, numerous drifters were captured or felt the influence of the AE. Figure 4 shows their low-pass filtered trajectories. The AE coherent clockwise circulation is remarkably depicted by the drifters. Most drifters were entrapped by the eddy and subsequently diverged in slowly increasing orbits before leaving after a few loops. There is one exception to this pattern for an SVP drifter (WMO 6102536; see heavy black track 
in Figure 4) which entered the eddy center on 18 June and stayed there until 7 July when, unfortunately, it stopped transmitting. This drifter depicted six loops while converging in a spiral motion, with radius roughly ranging from $30 \mathrm{~km}$ to only a few $\mathrm{km}$ and a period of 2-3 days.

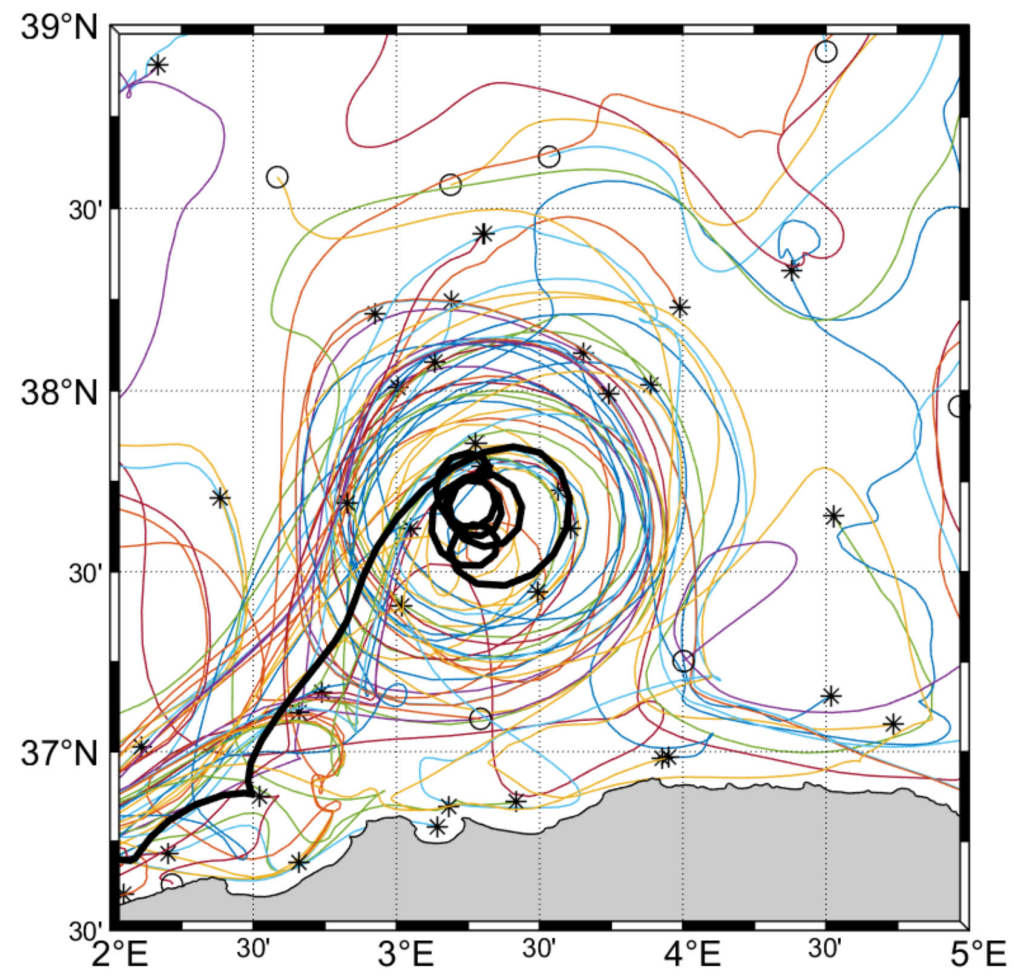

Figure 4. Low-pass filtered drifter tracks for June and July 2018 near the AE. Start and end locations are shown with circle and star symbols, respectively. The track of the SVP drifter (WMO 6102536) is shown in thick black.

Between 13 June and 4 July 2018, several drifters depicted the surface circulation in and around the $\mathrm{AE}$ centered around $3^{\circ} \mathrm{E} 15^{\prime}$ and $37^{\circ} \mathrm{N} 30^{\prime}$ (Figure 5). All drifter types were entrapped by the eddy, with a subsequent tendency to diverge in a spiraling motion. In total, 30 drifters were trapped in, or felt the influence of, the AE. After some time, drifters either stopped transmitting or eventually left the eddy, mostly to join the AC (see Figure 4 and panel of 4 July in Figure 5). Range in ADT is $\sim 30 \mathrm{~cm}$ between the center of the eddy and the background level. There is a qualitative agreement between the drifter tracks and the ADT isolines for all drifters, except for one DWS drifter (see drifter with green symbol in panel of 13 June in Figure 5) which moved to the $S$ and crossed the eddy. Since this drifter has no drogue it was probably pushed by the local wind and waves.

Drifter tracks and ADT data show that the eddy can be elliptical with speed varying with azimuth. An example map of AGV magnitude is shown in Figure 6a. The satellitederived geostrophic speed is maximum (near $50 \mathrm{~cm} / \mathrm{s}$ ) about $50 \mathrm{~km}$ from the eddy center in the northwestern and southeastern limbs of the eddy, whereas it is reduced to $30-40 \mathrm{~cm} / \mathrm{s}$ in the other directions. 


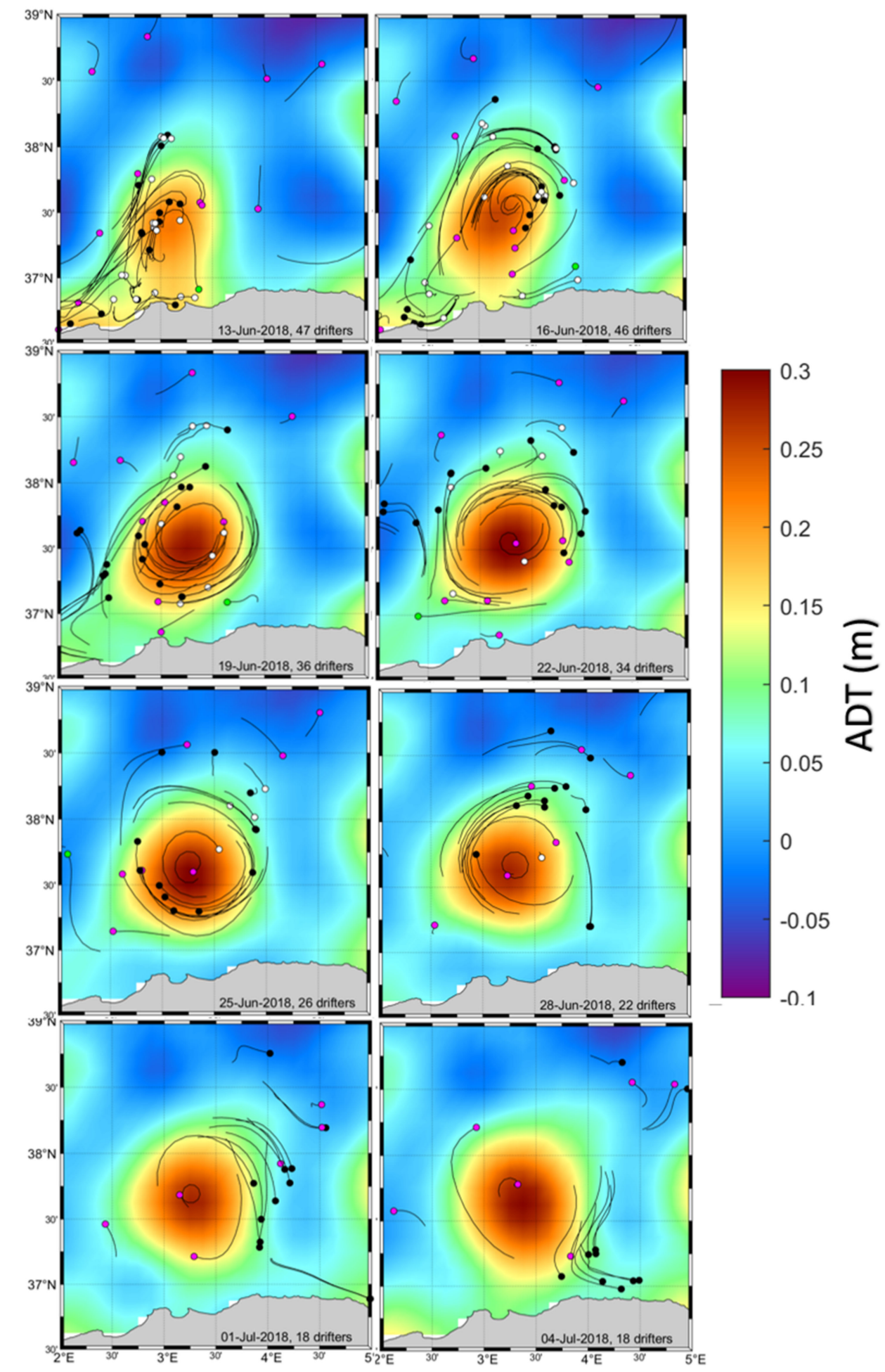

Figure 5. ADT maps between 13 June and 4 July 2018 in the vicinity of the AE with 3-day intervals. Superimposed are 3-day-long drifter trajectory segments centered on the respective days and ending with a color-coded circle symbol (black-CARTHE, white-CODE, green-DWSD and magentaSVP). The number of drifters in the shown area is posted. 

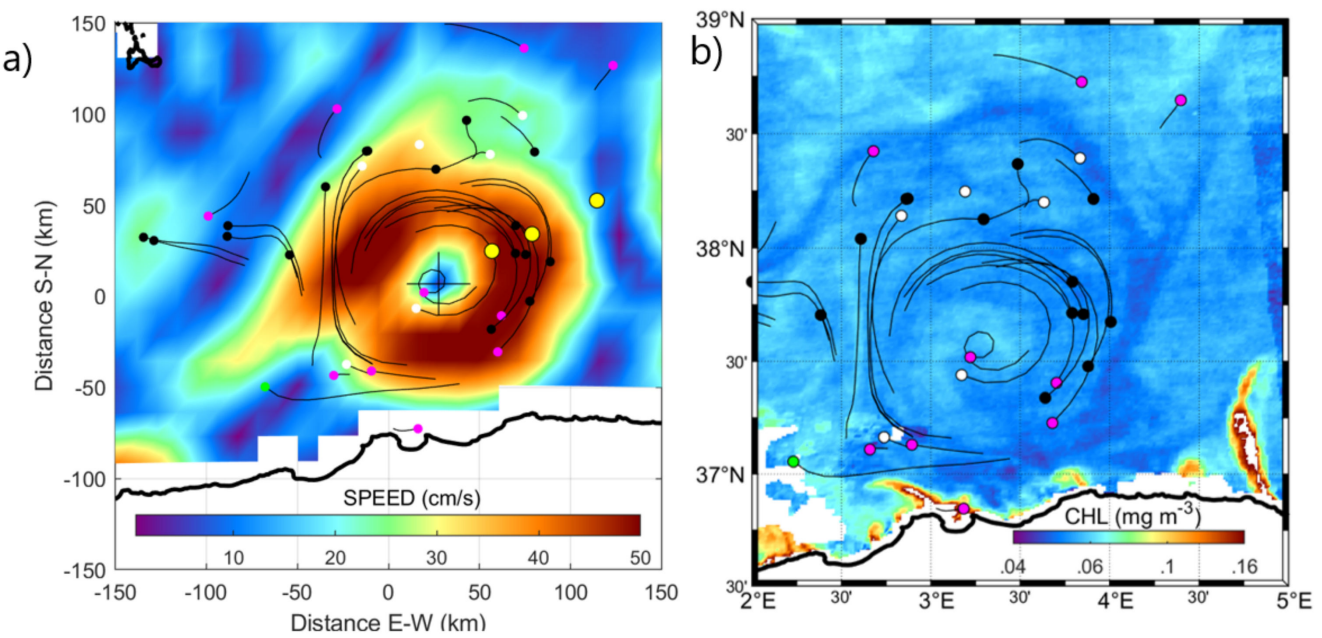

Figure 6. (a) AGV magnitude derived from satellite altimetry (colored pixels), with 3-day drifter track segments, on 22 June 2018. The cross symbol indicates the center of the AE (pixel with maximum ADT). The positions of the Argo profiles on 21-24 June are shown with yellow symbols. (b) Color-coded concentration of surface chlorophyll concentration from Moderate-Resolution Imaging Spectroradiometer (MODIS) satellite on 22 June 2018, superimposed with drifter track segments for 21-23 June. The circle symbols represent the drifter locations at the end of 23 June 2018.

When superimposed on satellite images of surface chlorophyll concentration, the drifter tracks align approximately with streaks or filaments of specific (high or low) chlorophyll values. Figure $6 \mathrm{~b}$ is an example on 22 June, showing the circular or spiraling structure and motion of the chlorophyll tracer around the AE. Except for the advection of low values of chlorophyll, the eddy itself does not have a strong impact on the chlorophyll and on the local biological productivity, at least in the surface waters.

In order to be more quantitative in the description of the AE kinematics, and in the comparison between the drifter and satellite altimetry data, several quantities were examined as a function of distance from the eddy center as determined by altimetry (location of ADT maximum, see Figure 5). We first assumed that the AE is a circular vortex. The tangential low-pass filtered velocities of the drifters are plotted versus radius at 3-day intervals between 13 June and 4 July in Figure 7. The satellite-derived geostrophic tangential velocities interpolated at the drifter locations are also plotted, as well as the azimuthally averaged geostrophic tangential speed. In the ideal case, all these values should be similar for a given radius. In reality, differences occur especially at large radius values, because of asymmetry or anisotropy in the flow field, the proximity of the coast to the south, ageostrophic and wind-driven velocity components and wind-waveinduced slippage.

Linear regressions forced through zero were computed for the drifter tangential velocities versus geostrophic tangential velocities for radius less than $100 \mathrm{~km}$ (see Table 1). Between 16 June and 1 July, the regression slope is essentially one and the root-mean-squareerror is bounded by $14 \mathrm{~cm} / \mathrm{s}$. The scatter diagram with regression line on 16 June is shown in Figure 8 (left panel). It is interesting to see whether the correction for wind-induced currents for the CARTHE and CODE drifters change the regression results. On 16 June, ERA5 winds were blowing from the E with a speed of $6 \mathrm{~m} / \mathrm{s}$. If we assume a correction of $\sim 6 \mathrm{~cm} / \mathrm{s}$ towards the $\mathrm{E}$ (1\% of wind speed [26]) and apply it to the CARTHE and CODE velocities, regression results improve slightly (RMSE of 10.6 instead of $10.9 \mathrm{~cm} / \mathrm{s}$; see Table 1 and Figure 8 right panel) but the difference is not statistically significant. This reveals that, for this case, corrections do not improve the mismatch between geostrophic and drifter velocities. 


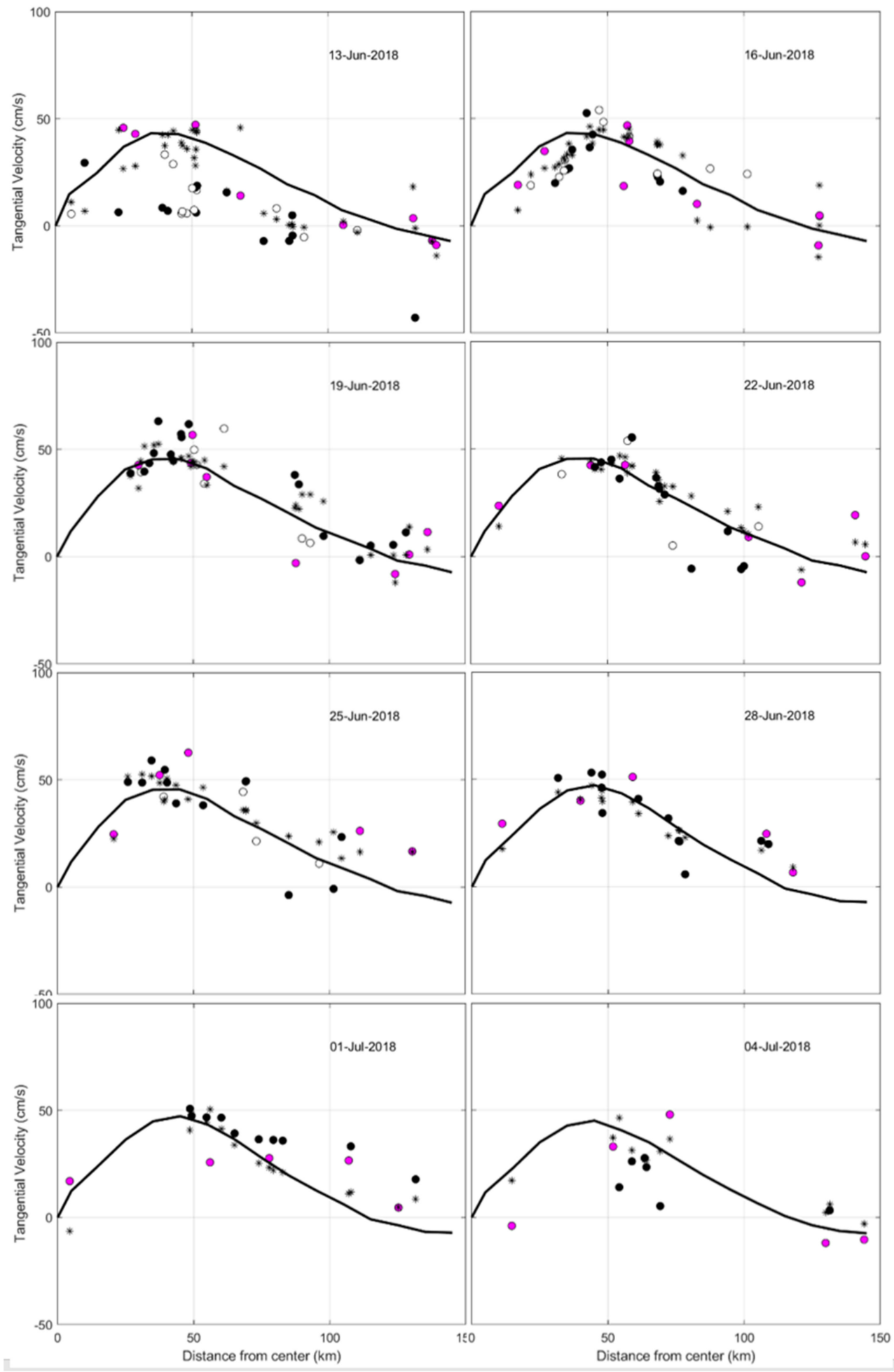

Figure 7. Clockwise tangential velocities versus distance from eddy center at 12:00 UTC on 13, 16, 19, 22, 25, 28 June 2018, 1 and 4 July 2018: drifter velocities (circle symbols: SVP-magenta, CODE-white, CARTHE-black); geostrophic velocities interpolated at the drifter locations (star symbols); geostrophic velocities averaged over all angles (black curve). 
Table 1. Linear regressions of drifter tangential velocities versus geostrophic tangential velocities forced through zero. Only points less than $100 \mathrm{~km}$ from the eddy center were considered. The slope (with standard error) and root-mean-square-error (RMSE) are listed. On 16 June, results using the CARTHE and CODE velocities corrected for slippage are also included.

\begin{tabular}{ccccc}
\hline Day & Number of Points & $\begin{array}{c}\text { Number of } \\
\text { Points }>\mathbf{~ 1 0 0 ~} \mathbf{~ k m}\end{array}$ & Slope & RMSE (cm/s) \\
\hline 13-Jun-2018 & 37 & 29 & $0.43 \pm 0.09$ & 14.3 \\
16-Jun-2018 & 30 & 26 & $0.87 \pm 0.06$ & 10.9 \\
16-Jun-2018* & 30 & 26 & $0.97 \pm 0.06$ & 10.6 \\
19-Jun-2018 & 32 & 25 & $1.03 \pm 0.06$ & 12.5 \\
22-Jun-2018 & 25 & 20 & $0.94 \pm 0.08$ & 13.4 \\
25-Jun-2018 & 22 & 17 & $1.04 \pm 0.07$ & 11.8 \\
28-Jun-2018 & 17 & 13 & $1.08 \pm 0.06$ & 8.3 \\
1-Jul-2018 & 15 & 11 & $1.04 \pm 0.12$ & 13.6 \\
4-Jul-2018 & 11 & 8 & $0.69 \pm 0.16$ & 14.8 \\
\hline
\end{tabular}

* applying windage corrections for CARTHE and CODE drifters.
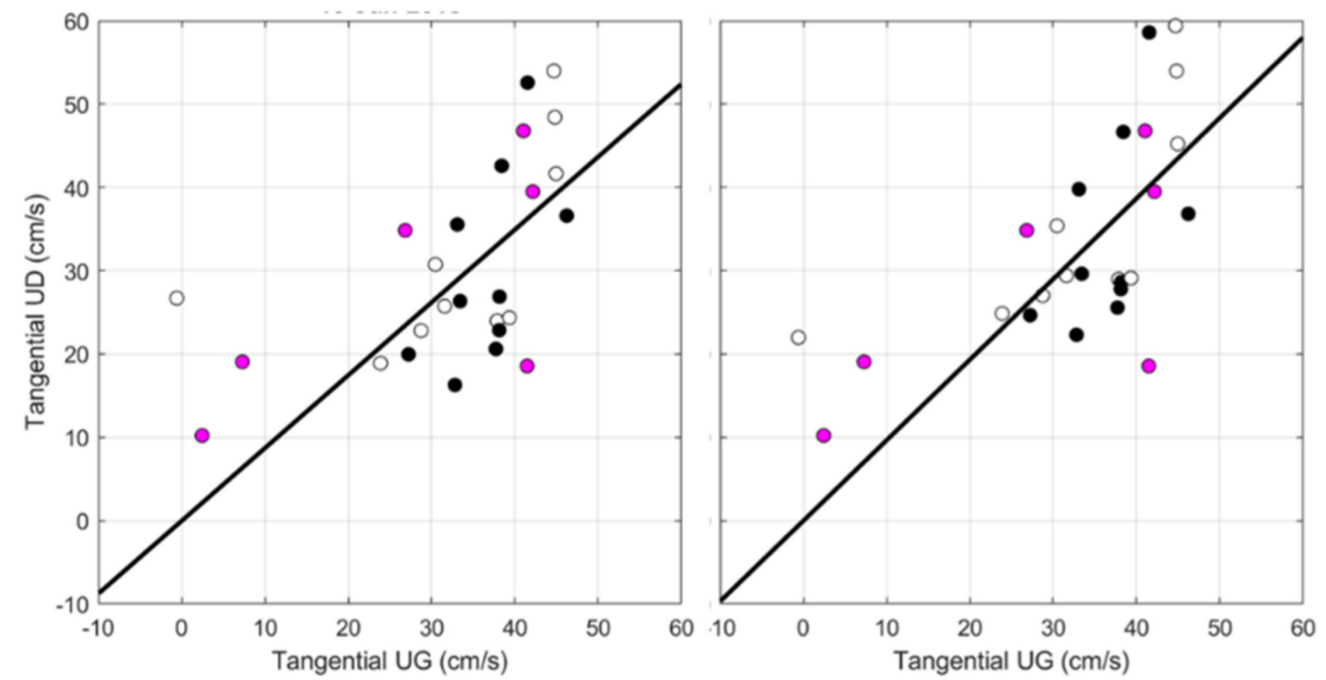

Figure 8. Left: Example of scatter diagram of tangential drifter (UD) and satellite-derived geostrophic tangential (UG) velocities on 16 June 2018 at 12:00 UTC. The straight line corresponds to the linear regression forced through zero (see Table 1). Right: Same but with the CARTHE and CODE velocities corrected for slippage.

Returning to Figure 7, the maximum clockwise geostrophic tangential speed ranges between 46 and $53 \mathrm{~cm} / \mathrm{s}$ at a radius of 30-60 km. The maximal extension of the eddy (zero crossing of the tangential velocity) varies between 113 and $122 \mathrm{~km}$. Drifter tangential velocities can be much larger than the geostrophic values, for instance between 16 and 25 June the drifter tangential velocities exceed altimetry-derived values by more than $10 \mathrm{~cm} / \mathrm{s}$. Maximal drifter tangential clockwise velocities vary between 47 and $63 \mathrm{~cm} / \mathrm{s}$.

To better describe quantitatively the morphology of the AE, we relaxed the circular assumption and applied two independent statistical methods to determine the characteristics of the drifter tracks in the eddy: least-squares fit of elliptical motion and wavelet ridge analysis (see details in the Appendix A).

Since the two methods provide similar results, only the results of the ellipse fitting method applied to 13 drifters trapped, with at least 1.5 loops in the AE, are reported here. The ellipse parameters are plotted versus time between 18 and 29 June 2018 in Figure 9. There is significant scatter in most parameters for all days. Between 18 and 24 June, the size of the drifter ellipses tends to increase from $\sim 30$ to $\sim 50 \mathrm{~km}$. Eccentricity varies quite a lot, but it is generally near 0.5 . Some drifter elliptical paths at specific times have an eccentricity near zero, corresponding to a near circle loop. The period also tends to increase 
with time from a daily mean value near 6 days on 18-19 June to 7-8 days after 20 June. The inclination of the drifter elliptical paths slowly decreases from about $40^{\circ}$ on 18 June to $-50^{\circ} 10$ days later. The low values of semi-major axis (near $10 \mathrm{~km}$ ), eccentricity $(\sim 0.2)$ and period (2-3 days) starting on 23 June coincide with the SVP drifter that was caught near the center of the eddy (WMO 6102536; see Figures 4 and 5). During the same period other drifters were rotating at the outside edge of the eddy with a semi-major axis increasing from 60 to $80 \mathrm{~km}$, and period increasing from 8 to 12 days.

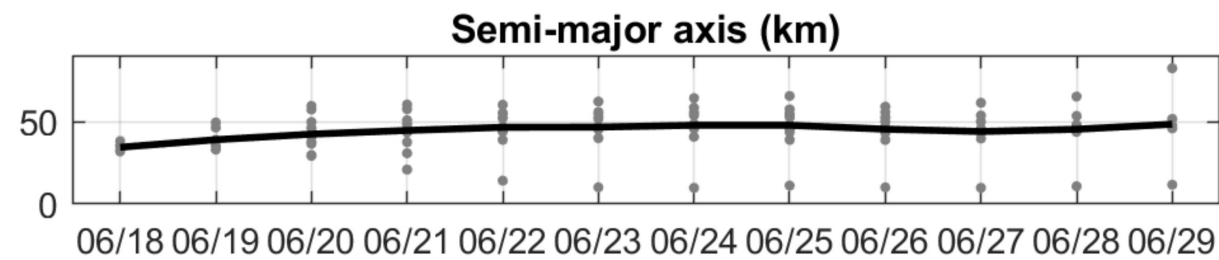

Eccentricity

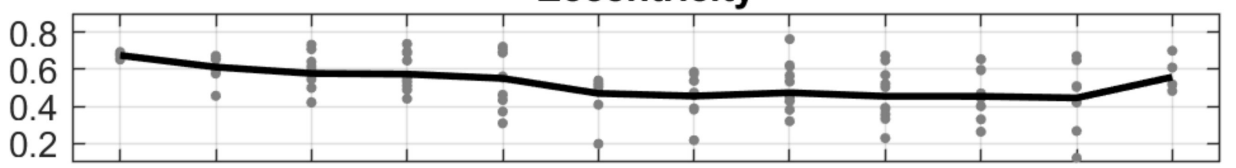

06/18 06/19 06/20 06/21 06/22 06/23 06/24 06/25 06/26 06/27 06/28 06/29

Inclination $\left({ }^{\circ}\right)$

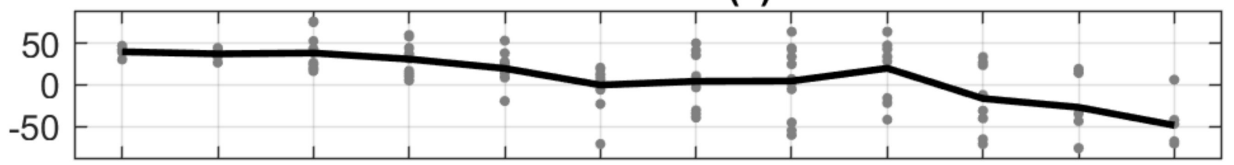

06/18 06/19 06/20 06/21 06/22 06/23 06/24 06/25 06/26 06/27 06/28 06/29

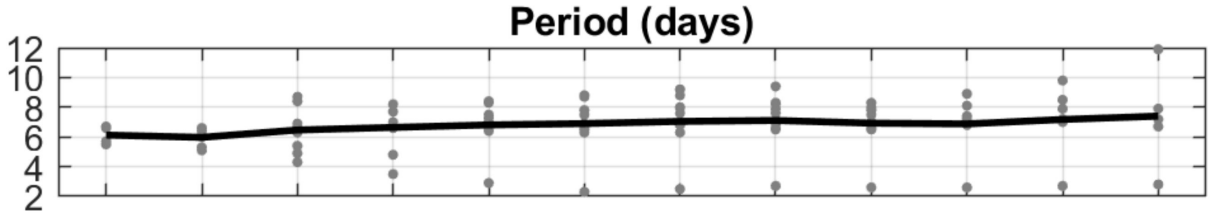

06/18 06/19 06/20 06/21 06/22 06/23 06/24 06/25 06/26 06/27 06/28 06/29

Figure 9. Daily ellipse parameters versus time for all the 13 drifters entrapped in the AE as estimated by the ellipse fit method: individual values (gray dots) and daily means (black lines). Results are shown only for a RMSE less than $10 \mathrm{~km}^{2}$.

The temporal variations of the ellipse parameters depend strongly on the position of the drifters within the eddy. It is therefore interesting to plot some ellipse parameters as a function of loop size or semi-major axis (a) (Figure 10). The rotation period appears to increase linearly with the ellipse size, from 2-3 days for $a=10 \mathrm{~km}$ to about 10 days for $a=65 \mathrm{~km}$. The minimum and maximum speeds of the drifters in the elliptical loops (see Appendix A) vary between 20 and $60 \mathrm{~cm} / \mathrm{s}$. They also generally slowly increase with distance from the eddy center. The average vorticity inside the elliptical drifter track was estimated using Equation (1) and was scaled by the value of the inertial frequency $(f)$ at the latitude of the center of the ellipse. It is negative and its magnitude varies between $0.6 f$ near the eddy center and $0.2 f$ for $a=50-60 \mathrm{~km}$. 

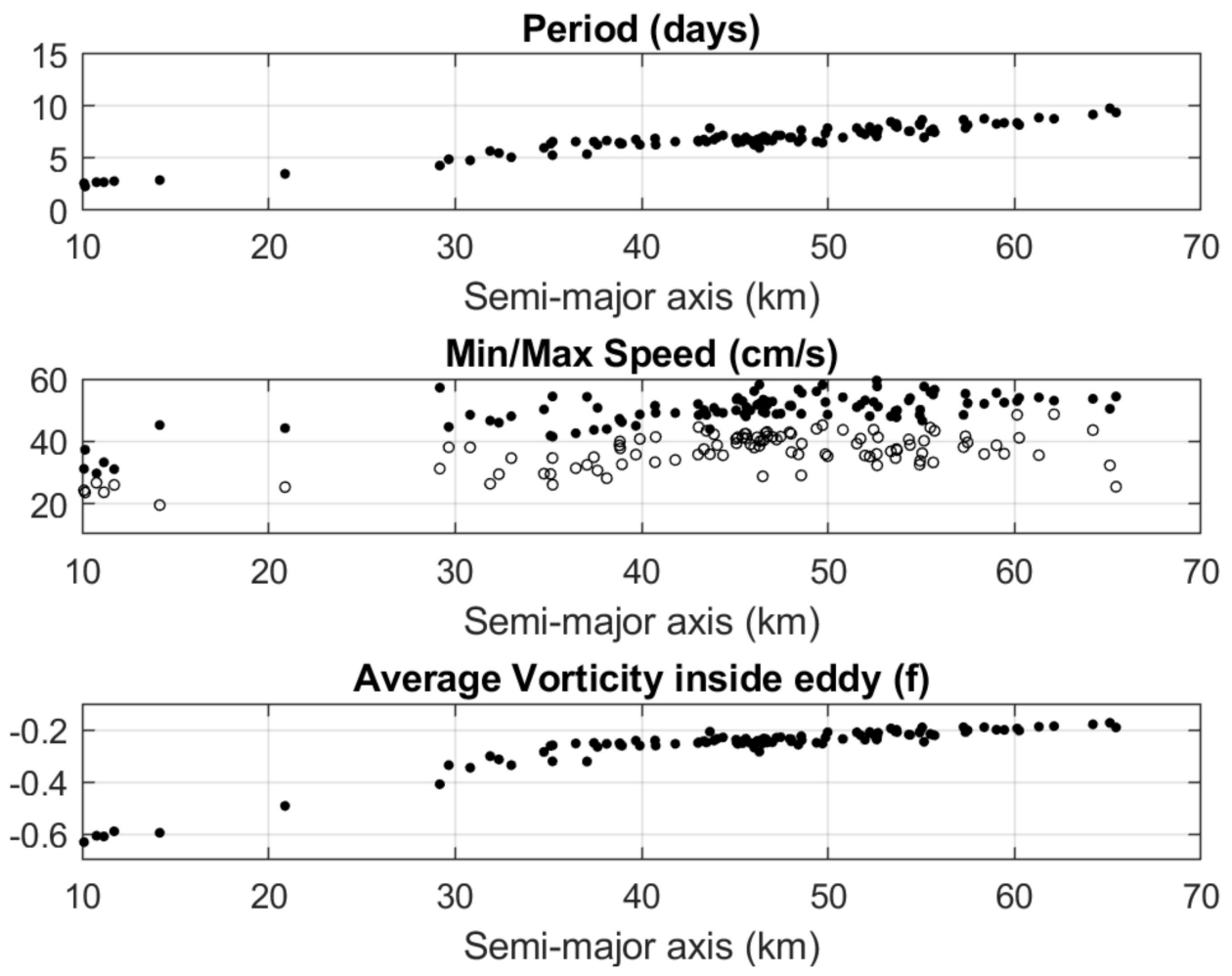

Figure 10. Period, minimum and maximum speeds and average vorticity as estimated from the drifter ellipses (for RMSE $<10 \mathrm{~km}^{2}$ only) in the AE between 18 and 29 June 2018. The scaling parameter for vorticity is the inertial frequency $(f)$ estimated at the center of the ellipses.

\subsubsection{Differential Kinematic Properties and Vertical Velocity in the Vicinity of the AE}

The surface divergence and vorticity were estimated using clusters of CODE and CARTHE drifters. Results for selected times are shown in Figure 11. On 21 June, a total of 301 clusters were considered. Vorticity is negative with a minimum near $0.22 f$ on the western side of the AE and is slightly positive (maximum of $0.04 f$ ) on the northern part, a little further away from the eddy center. Divergence is mostly positive (maximum of $0.15 f$ ) on the western and northern sides. A few days later, on 25 June, 257 clusters revealed a strong negative vorticity near the central core of the AE (minimum of $-0.28 f$ ). On the northern side, there is a large gradient of vorticity going from $\sim-0.20 f$ to $\sim 0.23 f$ with increasing distance from the center. There is a remarkable signature of convergence (negative divergence) on the northeastern side of the AE with values as low as $-0.23 f$. As expected, the aforementioned vorticity values are compatible with those obtained by taking derivatives of the AGV fields (right panels in Figure 11). The maximum negative vorticity computed from $\mathrm{AGV}$ is $-0.40 \mathrm{f}$ in the center of the AE core.

The vertical velocities near $100 \mathrm{~m}$ depth provided by the CMEMS OMEGA3D products are only available for the offshore northern part of the AE (Figure 12). However, they indicate a persistent positive velocity (upwelling) on the northwestern side and negative velocity (downwelling) on the northeastern side. These large-scale estimates are bounded by $2 \mathrm{~m} /$ day. 

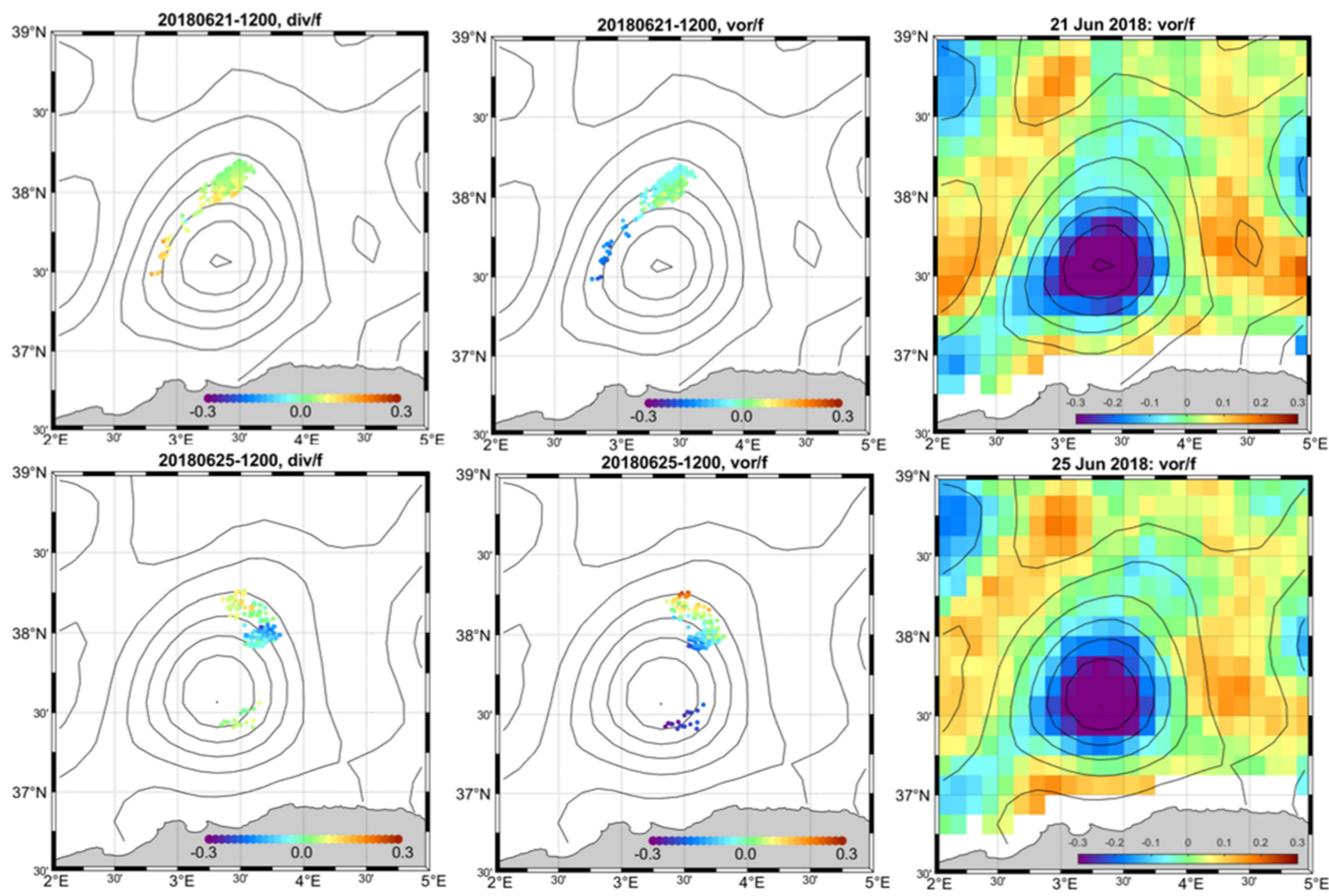

Figure 11. ADT maps of the AE at 12:00 UTC on 21 (top) and 25 (bottom) June 2018, shown with contour lines with $5 \mathrm{~cm}$ intervals, superimposed with estimates of surface divergence (left) and vorticity (middle) scaled by the local inertial frequency and plotted with colored symbols (right) at the centers of drifter clusters. Vorticity computed from AGV is shown with colored tiles in the right panels.

\subsubsection{Vertical Structure of the AE}

Between 21 and 24 June 2018, three Argo floats provided information on the vertical structure of the AE. They were located at distances of about 34,58 and $98 \mathrm{~km}$ from the center, i.e., approximately between the maximum swirl speed and just outside of the eddy (see Figure 13 and panel of 22 June in Figure 5). Note that the drift of the three floats is qualitatively compatible with the anticyclonic circulation of the AE. One of them (WMO 3901849) was trapped in the AE core for a couple of months (June-July 2018).

In terms of temperature (Figure 14), the float nearest the center (WMO 3901849) reveals slightly cooler surface water (by about $1^{\circ} \mathrm{C}$ ). Between 100 and $250 \mathrm{~m}$, the potential temperature $(\theta)$ is larger by about $1.5^{\circ} \mathrm{C}$ with respect to the outside float (WMO 3901907). Below $250 \mathrm{~m}$, the three floats show nearly identical potential temperatures. 

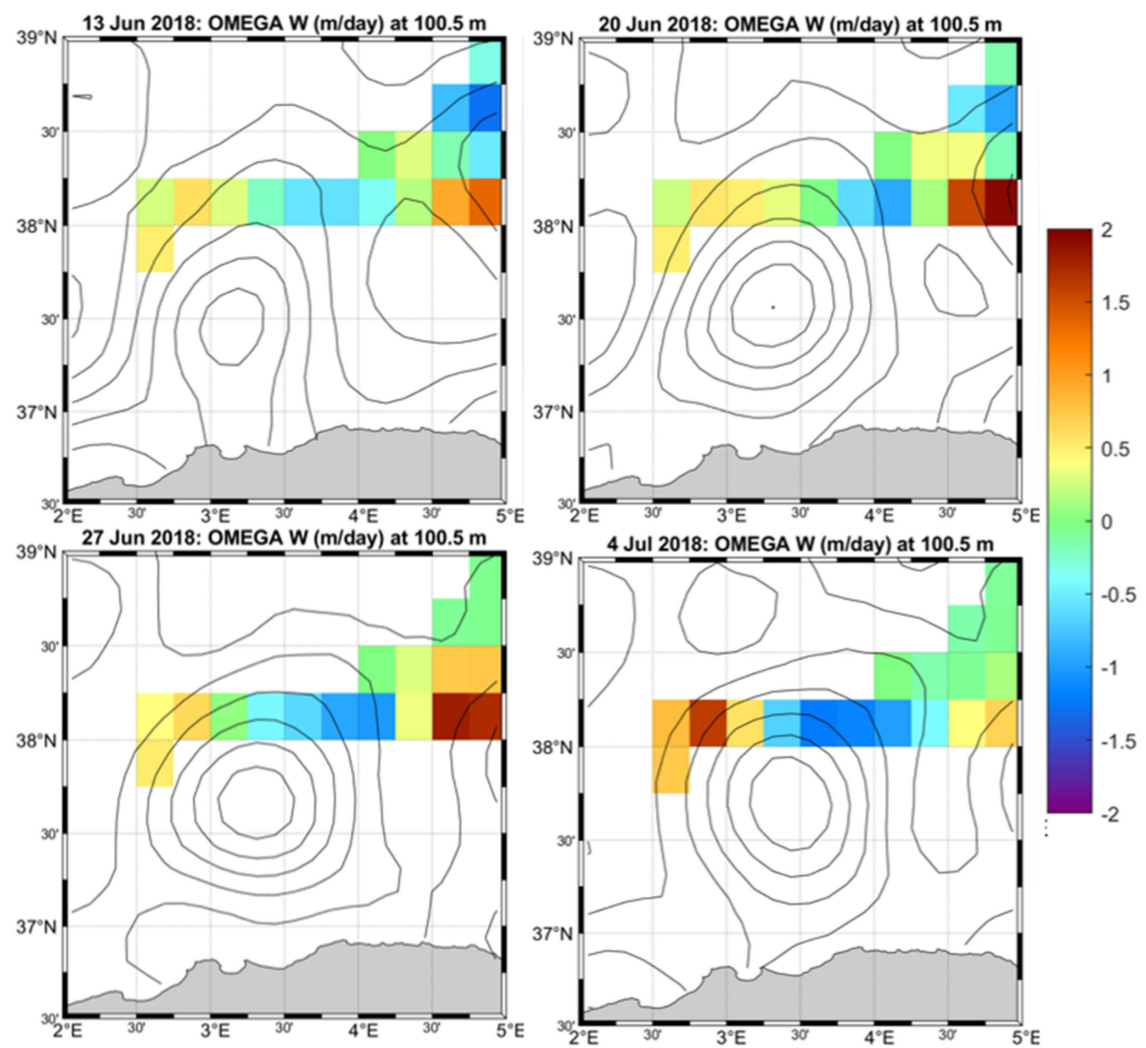

Figure 12. Maps of ADT (contour lines separated by $5 \mathrm{~cm}$ intervals) and estimates of the vertical velocity near $100 \mathrm{~m}$ depth as provided by the CMEMS OMEGA3D operational product (colored tiles) for 13, 20, 27 June and 4 July 2018.

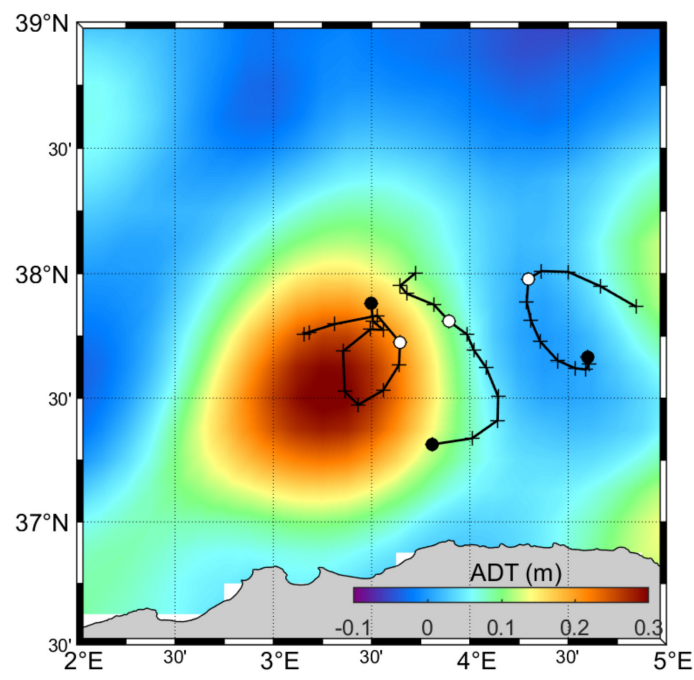

Figure 13. Argo float trajectories in June and July 2018 superimposed on an ADT map for 22 June 2018 with positions of the profiles (+symbols every 5 days). Black circles represent the positions of the last profiles. White circles represent the profiles, from left to right: WMO 3901849 (21 June), WMO 6901836 (24 June) and WMO 3901907 (22 June). 

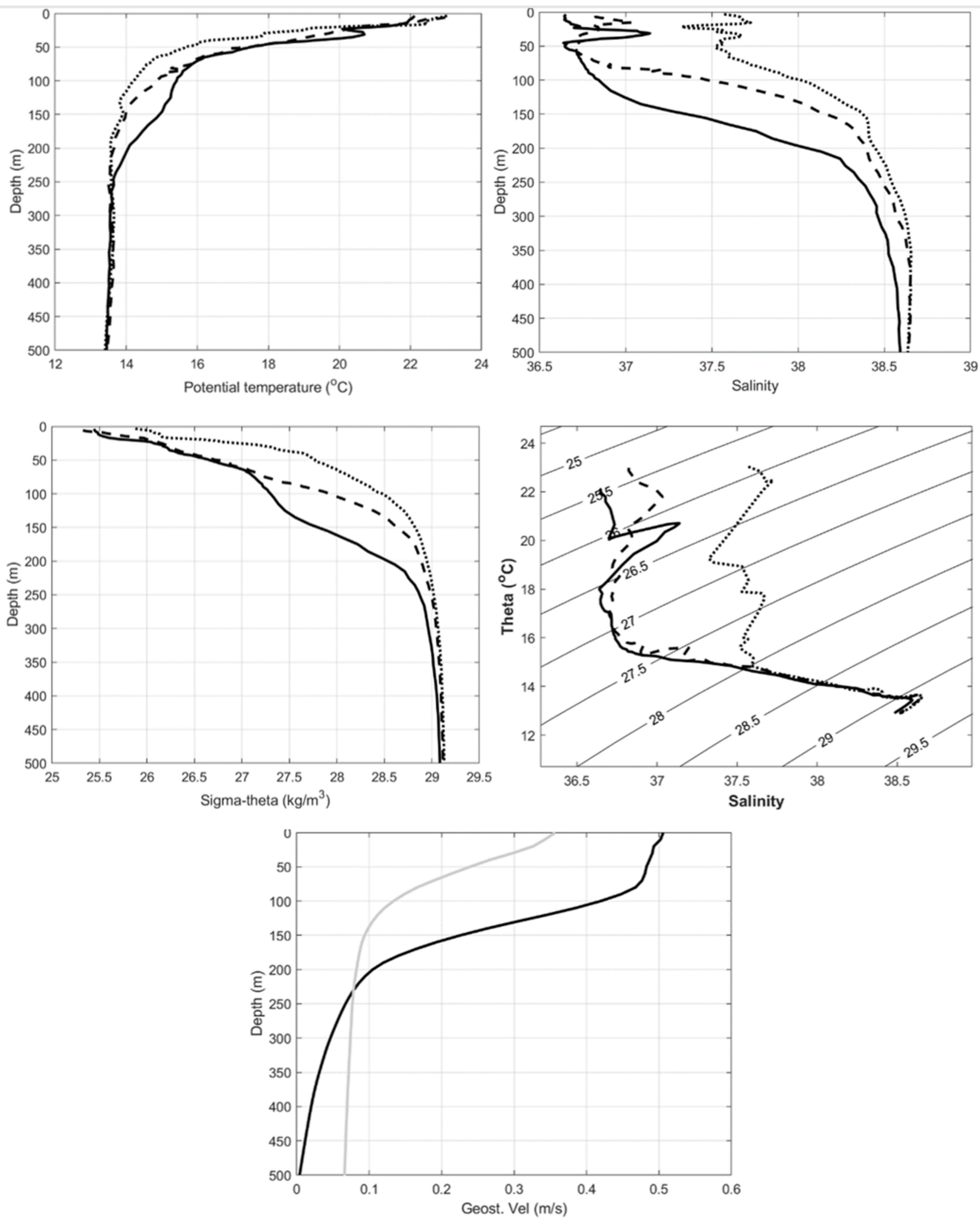

Figure 14. Top four panels: Profiles of potential temperature, salinity and potential density anomaly measured by three floats near the Algerian eddy: WMO 3901849 on 21 June (solid), WMO 6901836 on 24 June (dashed), and WMO 3901907 on 22 June (dotted). Corresponding $\theta-S$ diagram with isolines of potential density anomaly, using the entire profiles down to $2000 \mathrm{~m}$ depth. Bottom panel: Profiles of geostrophic velocities (positive in the SE direction) using pairs of density profiles (black: WMO 3901849-6901836, gray: WMO 6901836-3901907). Positive is southeastward. 
Salinity $(S)$ profiles (Figure 14) show that the eddy core is fresher in the entire water column, with a reduction in salinity of about 0.9 between the surface and $150 \mathrm{~m}$, decreasing to about 0.2 near 250 and about 0.04 at $500 \mathrm{~m}$. Note that a value of 0.04 in salinity is near the accuracy of Argo data (0.01 after DMQC). The lower salinity in the AE core confirms that it includes waters of Atlantic origin.

The potential density is mostly dominated by salinity; therefore, it is minimum nearest the center. Near the surface, there is a reduction from 25.9 to $25.3 \mathrm{~kg} \mathrm{~m}^{-3}$ in potential density anomaly. Near $60 \mathrm{~m}$ the reduction is $1 \mathrm{~kg} \mathrm{~m}^{-3}$, it increases to $1.3 \mathrm{~kg} \mathrm{~m}^{-3}$ near $120 \mathrm{~m}$ (where potential density anomaly in the eddy is about $27.4 \mathrm{~kg} \mathrm{~m}^{-3}$ ) and becomes insignificant below $250 \mathrm{~m}$ depth.

The $\theta-S$ diagram (Figure 14; using full profiles down to $2000 \mathrm{~m}$ depth) reveals that waters denser than $28 \mathrm{~kg} \mathrm{~m}^{-3}$ in potential density anomaly have the same temperaturesalinity relationship. This indicates that the three floats sampled the same intermediate water masses, which are subducted below the center of the $\mathrm{AE}$ (corresponding to the concave doming of the isopycnals). In the near-surface layer $(<50-150 \mathrm{~m})$ two water masses are distinct: the AW in the AE core with salinity of 36.5-37 and the Mediterranean water outside (with salinity near 37.5 ). The maximum salinity above 38.5 for deep waters with potential density anomaly in excess of $29 \mathrm{~kg} \mathrm{~m}^{-3}$ (see kink in the curves) is a signature of the underlying Levantine Intermediate Water (LIW).

The three potential density profiles were interpolated at common depths with $10 \mathrm{~m}$ intervals. The relative mean geostrophic velocities between pairs of profiles were estimated down to $500 \mathrm{~m}$ depth using the hydrostatic approximation and the thermal wind equation:

$$
\frac{\partial U_{g}}{\partial z}=\frac{g}{f \rho} \frac{\Delta \rho}{D}
$$

where $U g$ in the mean geostrophic velocity, $z$ is depth, $g$ is the gravity constant, $f$ is the inertial frequency, $\rho$ is density, $\Delta \rho$ is the density difference and $D$ is the distance between the profiles. The ADT at the profile locations was used to calculate the surface mean geostrophic velocity between the floats, and to obtain profiles of absolute geostrophic velocities (Figure 14, bottom panel). For the pair closest to the center of the AE (WMO 3901849-6901836) the mean distance from the AE center is about $50 \mathrm{~km}$ and corresponds to the maximum in orbital velocities (see Figures 5, 6a and 10). The mean geostrophic velocity is $47-51 \mathrm{~cm} / \mathrm{s}$ in the top layer down to about $80 \mathrm{~m}$. Below this layer, it decreases quickly to reach $10 \mathrm{~cm} / \mathrm{s}$ at $200 \mathrm{~m}$. At $500 \mathrm{~m}$, it essentially vanishes, corresponding to a level of no motion. For the other pair of profiles (WMO 6901836-3901907), further away from the AE center, the mean distance is $\sim 80 \mathrm{~km}$ and the mean surface geostrophic current is $35 \mathrm{~cm} / \mathrm{s}$. It reduces to $10 \mathrm{~cm} / \mathrm{s}$ near $125 \mathrm{~m}$ and reaches $7 \mathrm{~cm} / \mathrm{s}$ at $500 \mathrm{~m}$. Note that this pair is located in the outer edge of the $\mathrm{AE}$ where the surface geostrophic velocity decreases from 50 to $10-20 \mathrm{~cm} / \mathrm{s}$ and the vorticity is positive (Figures $6 \mathrm{a}$ and 7).

\section{Discussion}

Lagrangian data of drifters and float, along with operational oceanography products mainly based on satellite observations, provided a unique opportunity to study the morphology and kinematics of a specific AE in the southwestern Mediterranean Sea in 2018, with specific focus on the period June-July 2018.

ADT maps allowed us to track the AE from its generation as a meander of the AC in mid-May, and to describe its evolution as an independent vortex in June-July, moving at a typical speed of $2 \mathrm{~km} /$ day (Figure 2). In August, the AE interacted with another large vortex located more to the $\mathrm{E}$ (Figure 3). In October, it split into two components, one staying near the coast and forming a new meander of the AC, and the other drifting to the NW as an independent weak eddy, which eventually dissipated south of the Balearic Islands in late November (Figure 3).

The AE started to be sampled by the drifters when it was detaching from the AC on 13 June. About 30 drifters were involved in its clockwise circulation for a few weeks 
(Figures 4 and 5). Most drifters left the AE to rejoin the AC or stopped transmitting after 4 July.

Between 13 June and 4 July 2018, the AE was in the form of an independent vortex detached from the AC and with a typical contrast in ADT of $\sim 30 \mathrm{~cm}$ with respect to the background (Figure 5). The drifter tracks follow qualitatively well the ADT isolines. Some of them were trapped in the AE and described 1 to 6 loops in it, with some tendency to diverge from the eddy center for radii larger than $\sim 30 \mathrm{~km}$. In contrast, near the eddy center $(<15 \mathrm{~km})$, one SVP drifter depicted rotating loops with slight convergence (Figures 4 and 5). There is no evidence from the altimetry and drifter data of a cyclonic vortex to the west (upstream) of the AE when it is detaching from the AC as observed by [6] and simulated in a rotated tank [9]. If it existed, it must have been small, short-lived and repelling drifters.

Although ADT isolines and drifter indicated that the AE is not perfectly circular, we first assumed isotropic symmetry to estimate some quantitative characteristics of the vortex. Drifter and satellite-derived geostrophic velocities were compared in the tangential direction (Figures 7 and 8, Table 1). The RMSE between the two estimates vary between 8 and $15 \mathrm{~cm} / \mathrm{s}$ for speeds ranging between 10 and $60 \mathrm{~cm} / \mathrm{s}$. This is a good agreement, given the two different natures and horizontal resolutions of the velocity estimates. During that period, the ERA5 winds had speeds of 5-10 m/s, which would correspond to about $10 \mathrm{~cm} / \mathrm{s}$ difference between currents measured by CARTHE and CODE drifters and those, mainly geostrophic, deeper in the surface mixed layer [26]. This agreement proves that the $\mathrm{AE}$ is essentially in geostrophic balance, which is expected since the local Rossby number is less than one (see vorticity estimates below).

The satellite and drifter data demonstrate that the AE has a core in clockwise rotation with increasing speed as far as $40-50 \mathrm{~km}$ from its center with a maximum swirl speed near $50 \mathrm{~cm} / \mathrm{s}$ (Figures 6a and 7). Further away from the AE center the speed decreases and reaches negligible values near a radius of $100 \mathrm{~km}$. The eddy is thus characterized by negative vorticity inside $40-50 \mathrm{~km}$, and positive vorticity outside. These results are similar to those reported in [10] for another AE.

ADT maps and drifter tracks indicate that the AE is not perfectly circular, so we applied statistical techniques to fit elliptical paths to the drifter tracks when they are looping in the eddy. This method was only applicable for semi-major axes between 10 and $65 \mathrm{~km}$ since for larger distances no drifter executed a full loop. Indeed, results indicate that the eccentricity of the drifter loops is usually different from zero (see Figures 9 and A2) and its daily mean value varies between 0.4 and 0.7 . In general, both the ellipse size and rotation period tend to increase slowly with time: the semi-major axis (period) increases from $\sim 30 \mathrm{~km}$ ( 6 days) to $\sim 50 \mathrm{~km}$ (7.5 days) in less than a week (Figure 9 ). The inclination of the ellipses also shows some significant scatter (Figure 9), but there is some trend of slowly decreasing mean values (mostly visible between $50^{\circ}$ and $0^{\circ}$ on $18-24$ June), corresponding to the clockwise rotation of the ellipse axes of $\sim 10^{\circ} /$ day. Similar clockwise rotation was found, and analyzed theoretically, in Gulf Stream warm-core rings [42].

If we examine some ellipse parameters as a function of semi-major axis (Figure 10), we see that the period of rotation increases from 3 days (at $10 \mathrm{~km}$ ) to 10 days (at $65 \mathrm{~km}$ ). Again, these values are similar to those estimated by [10] for another AE. Hence, there is no indication from the drifter data of any solid body rotation with constant period. Consequently, the drifter speeds along the modelled elliptical tracks are also slightly increasing with distance from the AE center. The above-mentioned maximum speed of $50 \mathrm{~cm} / \mathrm{s}$ for a semi-major axis of $\sim 50 \mathrm{~km}$ is confirmed by the statistical method.

The average negative vorticity obtained with some drifters trapped near the AE center (distance less than $15 \mathrm{~km}$; see Figures 4, 5 and 10) can reach values near $-0.6 f$. As the size of the drifter loops increases (semi-major axis near $30 \mathrm{~km}$, and then to $65 \mathrm{~km}$, see Figure 11) there is contribution of less negative and positive local vorticity values, so that the average vorticity in the growing elliptical paths decreases slowly in magnitude to reach a mean vorticity of $-0.2 f$ near $60 \mathrm{~km}$. 
Vorticity was also estimated using clusters of drifters. Large negative values $(\sim-0.3 f)$ were found near the AE center (Figure 11), whereas positive values (up to $0.2 f$ ) dominated on the outside eddy edge. The large negative vorticity is generally smaller in magnitude with respect to previous estimates for two reasons: (1) the cluster method is using cluster sizes between 20 and $50 \mathrm{~km}$ so the results are smoothed; (2) it excludes the SVP drifters, in particular drifter WMO 6102536, which was trapped in a very small orbit near the AE center. It is, however, similar to the vorticity estimated from the AVG (right panels in 11).

Surface divergence estimated with the cluster method revealed areas of divergence (convergence) on the northwestern (northeastern) sides of the $\mathrm{AE}$, with maximum values of $0.15 f(0.23 f)$ (Figure 11). This pattern qualitatively coincides with that of the vertical velocity estimated using ARMOR3D products and the OMEGA equation (Figure 12) and agrees with the QG theory showing secondary circulation with upwelling (downwelling) upstream (downstream) of a meandering current [43-45].

Finally, Argo floats revealed that the AE has a vertical extension of about $250 \mathrm{~m}$ with a warm, fresh and light signature in its core (Figures 13 and 14). Between the surface and $250 \mathrm{~m}$ depth, the maximum geostrophic speed varies from $\sim 50 \mathrm{~cm} / \mathrm{s}$ (at the surface) to about $10 \mathrm{~cm} / \mathrm{s}$. Near the surface the water is cooler inside, but its salinity is low enough $(<37)$ to keep the water light and prevent it from sinking by convection. Salinity maxima in the water column, corresponding to the LIW, are found near 550 and $400 \mathrm{~m}$ depth inside and outside the AE, respectively. It is speculated that the LIW sinking is along isopycnals which are deepening below the $\mathrm{AE}$, as observed by [10], but the low salinity accuracy $(\sim 0.1)$ of the Argo profiles does not allow us to confirm this statement.

\section{Conclusions}

This paper demonstrates that Lagrangian in situ data provided by drifters and floats, in concert with available operational oceanography products, are an efficient approach to study ocean eddies, if they are utilized in large numbers and remain some time in and near these circulation structures. Most results obtained here on the morphology and kinematics of a specific AE in the southwestern Mediterranean Sea are similar to those previously obtained on other AEs using a ship-based hydrographic survey [10] or glider measurements [11]. However, a multi-platform in situ approach is advocated for future more comprehensive investigations of ocean eddies using research vessels, autonomous moving platforms (drifter, floats, gliders) and satellite remote sensing and operational products.

Author Contributions: Conceptualization, P.-M.P.; methodology, P.-M.P. and D.T.; formal analysis, P.-M.P. and D.T.; investigation, P.-M.P., L.C. and T.Ö.; resources, P.-M.P., L.C. and T.Ö.; data curation, M.M. and G.N.; writing — original draft preparation, P.-M.P.; writing—review and editing, L.C., T.Ö., D.T., A.P., S.R., E.M., M.M. and G.N., funding acquisition, P.-M.P., L.C. and T.Ö. All authors have read and agreed to the published version of the manuscript.

Funding: This research was mainly funded by the US Office of Naval Research (ONR) as part of the CALYPSO Departmental Research Initiative through grants N00014-18-1-2418 and N00014-18-1-2138. LC and the SVP drifters were funded by ONR grants N00014-17-1-2517 and N00014-19-1-269. D.T., A.P. and S.R. were funded by ONR grant N00014-16-1-3130.

Data Availability Statement: The drifter data used in this study are available on the CALYPSO web cloud. The Argo float data and metadata can be downloaded from the Argo GDAC.

Acknowledgments: The authors are grateful to all the people who have deployed drifters and floats, and made their data available, in the southwestern Mediterranean Sea. Special thanks to Antonio Bussani for processing the drifter and float data. The satellite altimetry and chlorophyll data and OMEGA3D products were obtained from the Copernicus Marine Environment Monitoring Service (CMEMS) website: https://marine.copernicus.eu. The ERA5 reanalysis products were downloaded from the Copernicus Climate Data Store (https://cds.climate.copernicus.eu). The Argo float data were collected and made freely available by the International Argo Program and the 
national programs that contribute to it (e.g., ArgoItaly funded by the Italian Ministry of University and Research, and MOCCA sponsored by the European Maritime and Fisheries Fund-EMFF).

Conflicts of Interest: The authors declare no conflict of interest. The funders had no role in the design of the study; in the collection, analyses, or interpretation of data; in the writing of the manuscript, or in the decision to publish the results.

\section{Appendix A. Fitting an Elliptical Path to a Drifter Looping Track}

The low-pass filtered data of 13 drifters trapped in the AE during the second half of June 2018 were used to estimate the main characteristics of the looping track segments. We used the following two statistical methods.

\section{A.1. Least-Squares Fitting of Elliptical Track}

For each day between 18 and 29 June, a segment of 10 days for each drifter centered on that day was considered. For one drifter with a priori smaller rotation period near 2-3 days (SVP drifter WMO 6102536), this time window was reduced to 4 days. For the others the choice of 10 days was adequate because the period ranges in 5-10 days. The following elliptical path with a linearly moving center was fitted to this segment (using complex notation):

$x+i y=x_{o}+i y_{o}+(U+i V)\left(t-t_{o}\right)+A \exp \left(\frac{2 \pi i\left(t-t_{o}\right)}{P}\right)+B \exp \left(\frac{-2 \pi i\left(t-t_{o}\right)}{P}\right)+$ error

where $x+i y$ is the position at time $t, x_{o}+i y_{0}$ is the position at time $t_{0}, U+i V$ the mean velocity, $P$ is the period, and $A / B$ are the amplitudes of the counterclockwise and clockwise rotations, respectively. Taking the first derivative in time of Equation A1, we obtain the following model for the drifter velocity $u+i v$ :

$$
u+i v=(U+i V)+\frac{2 \pi i}{P} A \exp \left(\frac{2 \pi i\left(t-t_{o}\right)}{P}\right)-\frac{2 \pi i}{P} B \exp \left(\frac{-2 \pi i\left(t-t_{o}\right)}{P}\right)+\text { error }
$$

Equation (A1) was solved in the least-squares sense for values of $P$ ranging in 1-16 days, with an interval of 0.1 day. The best fit corresponds to $P$, and values of $x_{0}$, $y_{0}, u, v, A, B$, giving the maximum explained variance (or the minimum mean squared error $\left.\mathrm{MSE}=\operatorname{abs}(\text { error })^{2}\right)$.

An example for the CARTHE drifter ONR0445 is shown in Figure A1. The track of this drifter when trapped by the anticyclonic eddy is well modeled as an elliptical path whose center is moving slowly to the $\mathrm{N}$ and $\mathrm{E}$. The semi-major axis $(a)$, semi-minor axis $(b)$, eccentricity $\varepsilon$ and inclination $\theta$ were estimated as:

$$
\begin{gathered}
a=|A|+|B| \\
b=|| A|-| B|| \\
\varepsilon=\sqrt{1-b^{2} / a^{2}} \\
\theta=0.5(\operatorname{angle}(A)-\operatorname{angle}(B))
\end{gathered}
$$

They are plotted versus time in Figure A2. The semi-major axis varies between 46 and $55 \mathrm{~km}$. The eccentricity is $0.4-0.7$ and the period varies between 6.5 and 8.2 days. The inclination shows a slow clockwise rotation of the elliptical path. The MSE (not shown) is bounded by $60 \mathrm{~km}^{2}$. 


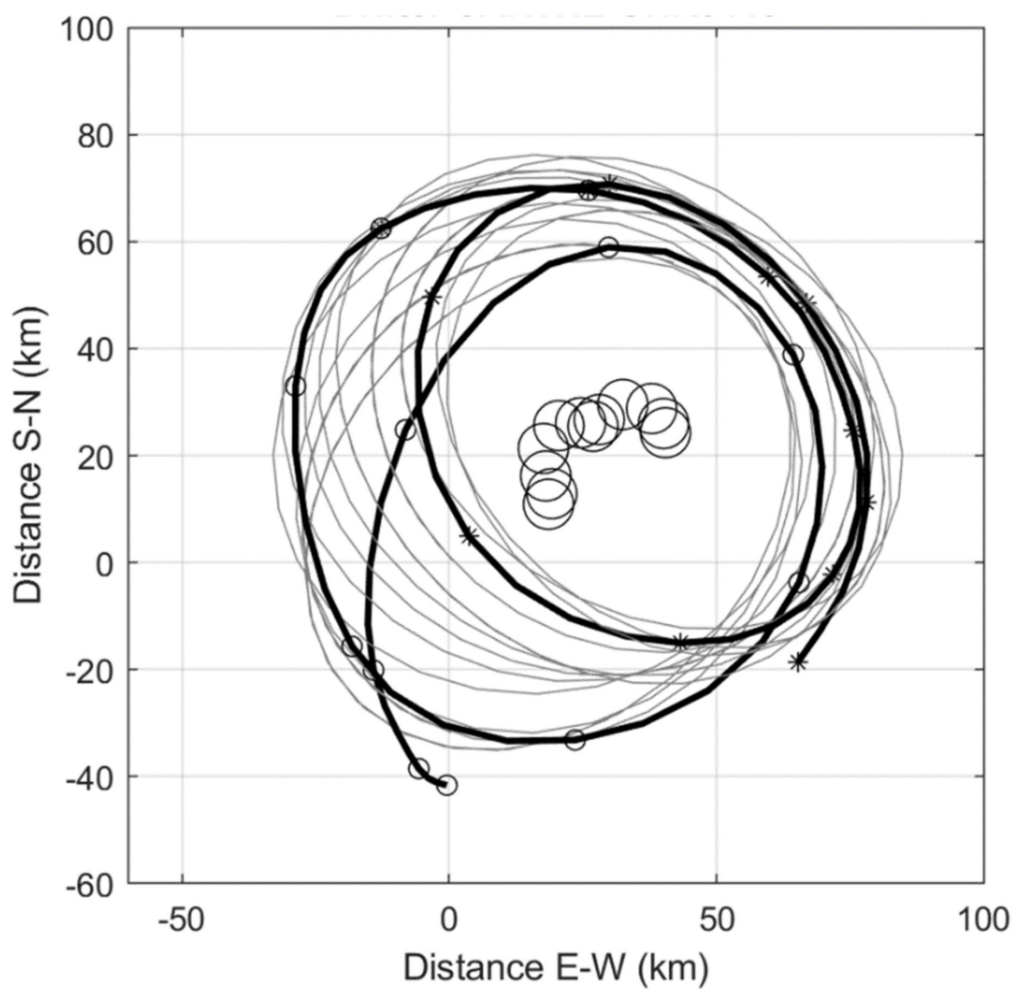

Figure A1. Example of ellipse fitting for drifter aONR0445. The drifter track between 13 June and 4 July is shown in black (with clockwise rotation). Small circle and star symbols denote the start and end of 10-day segments shifted every day. Daily elliptical paths are shown in gray, with their centers depicted with black circles.
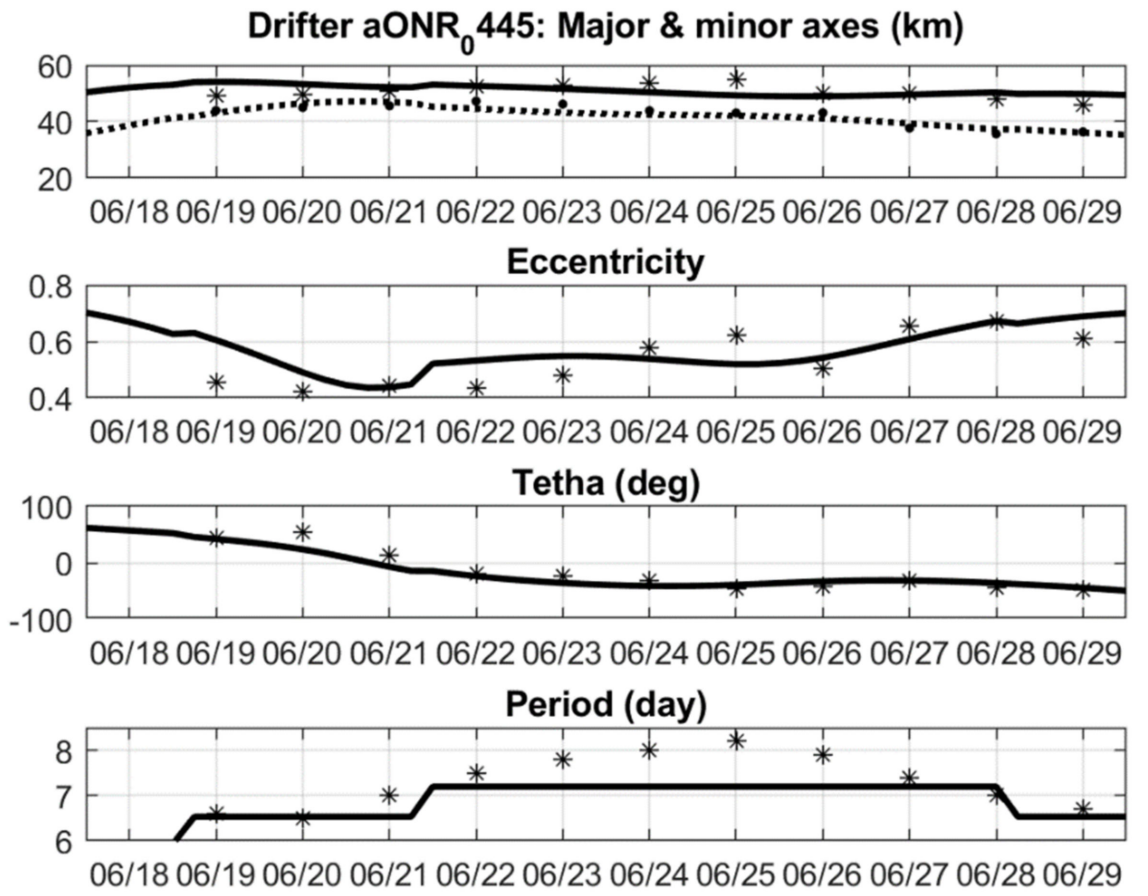

Figure A2. Ellipse parameters for drifter aONR0445 versus time as estimated by the least-squares fitting (star and dot symbols) and the wavelet ridge (solid and dotted curves) methods. 


\section{A.2. Wavelet Ridge Analysis}

Another method to characterize elliptical motion in drifter tracks is through wavelet ridge analysis $[46,47]$. We first computed the bivariate wavelet continuous transforms of the position and velocity time series using generalized Morse wavelets. The method was applied to the entire tracks of the drifters. Positions were transformed into zonal and meridional distances with respect to the mean position for each drifter. The results for drifter aONR0445 are depicted in Figure A3. A maximum is striking for the anticyclonic wavelets between 17 June and 1 July 2018.

A ridge detection algorithm was applied to identify the ridges in the wavelet transforms. They are shown with black curves in Figure A3 for the negative (anticyclonic) wavelets. The periods of the main ridge are plotted versus time in Figure A3 (lower panel).

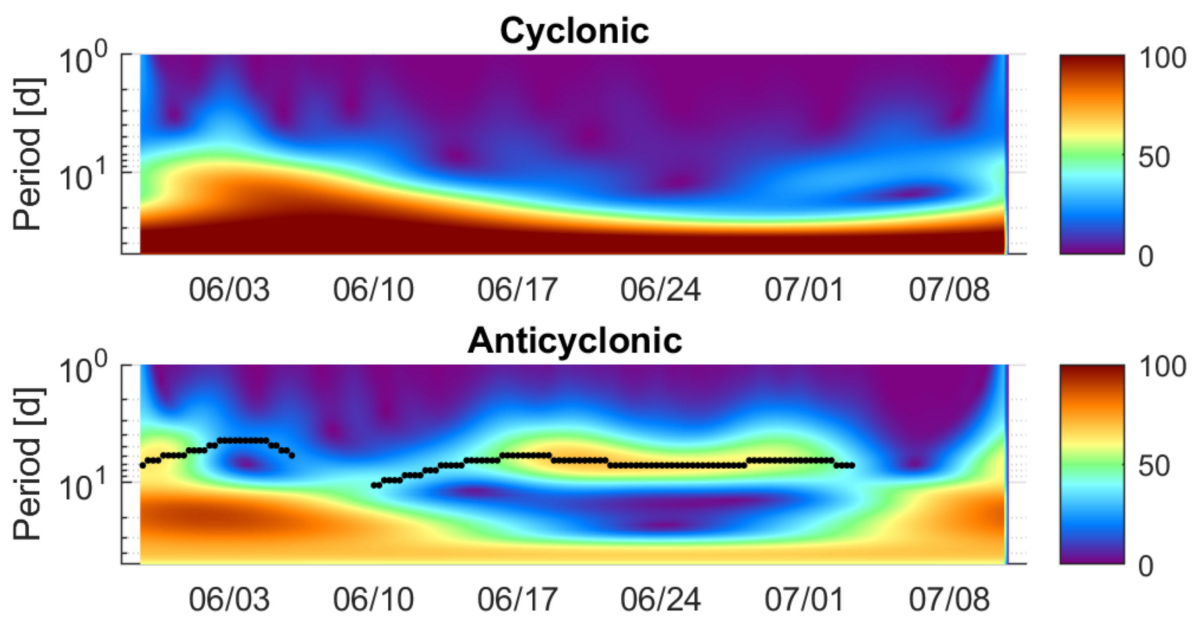

Figure A3. Top: Positive/cyclonic (top) and negative/anticyclonic (bottom) rotary wavelet transform amplitudes (in $\mathrm{km}$ ) versus time and period for the position time series of drifter aONR0445. Black curves represent the main ridges for the negative wavelets.

The corresponding ellipse parameters were computed using the values of the positive and negative transforms along the ridge of the negative wavelet transforms using the following equations [44]:

$$
\begin{gathered}
a=(|w n|+|w p|) / \sqrt{ } 2 \\
b=(|w n|-|w p|) / \sqrt{ } 2 \\
\theta=0.5(\operatorname{angle}(w p)-\operatorname{angle}(w n))
\end{gathered}
$$

where $w n$ and $w p$ are the negative and positive rotary wavelet transforms, respectively. We found that $a \approx 50 \mathrm{~km}, b \approx 45 \mathrm{~km}$, the eccentricity is near 0.5 and the period is $6.5-7.5$ days (Figure A2).

Figure A2 shows that the ellipse parameters estimated by the two methods are similar, although the wavelet ridge method tends to be a little smoother in time. In general, the semi-major and semi-minor axes are, respectively, $45-55 \mathrm{~km}$ and $35-45 \mathrm{~km}$. Eccentricity varies between 0.4 and 0.7 and the ellipse inclination decreases from about $50^{\circ}$ down to $-50^{\circ}$ in 10 days. The period of rotation is $6.5-8$ days.

\section{References}

1. Glenn, S.M.; Ebbesmeyer, C.C. Drifting buoy observations of a loop current anticyclonic eddy. J. Geophys. Res. Space Phys. 1993, 98, 20105-20119. [CrossRef]

2. Sanderson, B.G. Structure of an eddy measured with drifters. J. Geophys. Res. Space Phys. 1995, 100, 6761-6776. [CrossRef]

3. Matteoda, A.M.; Glenn, S.M. Observations of recurrent mesoscale eddies in the eastern Mediterranean. J. Geophys. Res. Space Phys. 1996, 101, 20687-20709. [CrossRef] 
4. Brassington, G.B. Estimating Surface Divergence of Ocean Eddies Using Observed Trajectories from a Surface Drifting Buoy. J. Atmos. Ocean. Technol. 2010, 27, 705-720. [CrossRef]

5. Shapiro, G.; Barton, E.D.; Meschanov, S.L. Capture and release of Lagrangian floats by eddies in shear flow. J. Geophys. Res. Space Phys. 1997, 102, 27887-27902. [CrossRef]

6. Millot, C. Circulation in the Western Mediterranean Sea. J. Mar. Syst. 1999, 20, 423-442. [CrossRef]

7. Millot, C.; Taupier-Letage, I.; Benzohra, M. The Algerian eddies. Earth Sci. Rev. 1990, 27, 203-219. [CrossRef]

8. Benzorha, M.; Millot, C. Hydrodynamics of an open sea Algerian eddy. Deep Sea Res. I 1995, 42, 1831-1847. [CrossRef]

9. Obaton, D.; Millot, C.; Chabert D'Hières, G.; Taupier-Letage, I. The Algerian current: Comparison between in situ and laboratory data sets. Deep Sea Res. I 2000, 47, 2159-2190. [CrossRef]

10. Ruiz, S.; Font, J.; Emelianov, M.; Isern-Fontanet, J.; Millot, C.; Salas, J.; Taupier-Letage, I. Deep structure of an open sea eddy in the Algerian Basin. J. Mar. Syst. 2002, 33-34, 179-195. [CrossRef]

11. Cotroneo, Y.; Aulicino, G.; Ruiz, S.; Pascual, A.; Budillon, G.; Fusco, G.; Tintoré, J. Glider and satellite high resolution monitoring of a mesoscale eddy in the algerian basin: Effects on the mixed layer depth and biochemistry. J. Mar. Syst. 2016, 162, 73-88. [CrossRef]

12. Puillat, I.; Taupier-Letage, I.; Millot, C. Algerian Eddies lifetime can near 3 years. J. Mar. Syst. 2002, 31, 245-259. [CrossRef]

13. Menna, M.; Gerin, R.; Bussani, A.; Poulain, P.-M. The OGS Mediterranean Drifter Database: 1986-2016; Istituto Nazionale di Oceanografia e di Geofisica Sperimentale: Trieste, Italy, 2017; p. 34.

14. Mahadevan, A.; Pascual, A.; Rudnick, D.L.; Ruiz, S.; Tintoré, J.; D’Asaro, E. Coherent Pathways for Vertical Transport from the Surface Ocean to Interior. Bull. Am. Meteorol. Soc. 2020, 101, E1996-E2004. [CrossRef]

15. Poulain, P.-M.; Özgökmen, T.; Guigand, C.; Wirth, N.; Casas, B.; Centurioni, L. CALYPSO Pilot Experiment 201827 May-2 June 2018 R/V ALLIANCE \& R/V SOCIB: Lagrangian Drifter and Float Deployments; Istituto Nazionale di Oceanografia e di Geofisica Sperimentale: Trieste, Italy, 2018; p. 22.

16. Niiler, P.P. The World Ocean Surface Circulation. Ocean Circulation and Climate: Observing and Modelling the Global Ocean; Siedler, G., Church, J., Gould, J., Eds.; International Geophysics Series; Academic Press: Cambridge, MA, USA, 2001; Volume 77, pp. 193-204.

17. Kirwan, J.A.D.; Rossby, T.; Lumpkin, R.; Pazos, M.; Bower, A.; Furey, H.; Grodsky, S.; Carton, J.; Centurioni, L.R.; Niiler, P.P.; et al. Lagrangian Analysis and Prediction of Coastal and Ocean Dynamics. In Lagrangian Analysis and Prediction of Coastal and Ocean Dynamics; Cambridge University Press: Cambridge, UK, 2007; pp. 39-67.

18. Centurioni, L.R. Drifter Technology and Impacts for Sea Surface Temperature, Sea-Level Pressure, and Ocean Circulation Studies, in Observing the Oceans in Real Time; Venkatesan, R., Tandon, A., D’Asaro, E., Atmanand, M.A., Eds.; Springer: Cham, Switzerland, 2018; pp. 37-57.

19. Niiler, P.P.; Sybrandy, A.S.; Bi, K.; Poulain, P.-M.; Bitterman, D. Measurements of the water-following capability of holey-sock and TRISTAR drifters. Deep. Sea Res. Part I Oceanogr. Res. Pap. 1995, 42, 1951-1964. [CrossRef]

20. Poulain, P.-M.; Gerin, R.; Mauri, E.; Pennel, R. Wind Effects on Drogued and Undrogued Drifters in the Eastern Mediterranean. J. Atmos. Ocean. Technol. 2009, 26, 1144-1156. [CrossRef]

21. Centurioni, L.; Braasch, L.; Di Lauro, E.; Contestabile, P.; De Leo, F.; Casotti, R.; Franco, L.; Vicinanza, D. a New Strategic Wave Measurement Station off Naples Port Main Breakwater. Coast. Eng. Proc. 2017, 1, 36. [CrossRef]

22. Davis, R.E. Drifter observations of coastal surface currents during CODE: The method and descriptive view. J. Geophys. Res. Space Phys. 1985, 90, 4741-4755. [CrossRef]

23. Poulain, P.-M. Drifter observations of surface circulation in the Adriatic Sea between December 1994 and March 1996. J. Mar. Syst. 1999, 20, 231-253. [CrossRef]

24. Poulain, P.-M.; Gerin, R. Assessment of the Water-Following Capabilities of CODE Drifters Based on Direct Relative Flow Measurements. J. Atmos. Ocean. Technol. 2019, 36, 621-633. [CrossRef]

25. Novelli, G.; Guigand, C.M.; Cousin, C.; Ryan, E.; Laxague, N.J.M.; Dai, H.; Haus, B.K.; Özgökmen, T.M. A Biodegradable Surface Drifter for Ocean Sampling on a Massive Scale. J. Atmos. Ocean. Technol. 2017, 34, 2509-2532. [CrossRef]

26. Poulain, P.-M.; Centurioni, L.; Özgökmen, T. Comparing the currents measured by CARTHE, CODE and SVP drifters as a function of wind and wave conditions in the southwestern Mediterranean Sea. J. Atmos. Ocean. Technol 2021, Submitted.

27. Menna, M.; Poulain, P.-M.; Bussani, A.; Gerin, R. Detecting the drogue presence of SVP drifters from wind slippage in the Mediterranean Sea. Measurement 2018, 125, 447-453. [CrossRef]

28. Argo. Argo Float Data and Metadata from Global Data Assembly Centre (Argo GDAC); SEANOE: Issy-les-Moulineaux, France, 2021. [CrossRef]

29. Wong, A.L.S.; Johnson, J.M.; Owens, W.B. Delayed-mode calibration of autonomous CTD profiling float salinity data $\theta-S$ climatology. J. Atmos. Ocean. Tech. 2003, 20, 308-318. [CrossRef]

30. Böhme, L.; Send, U. Objective analyses of hydrographic data for referencing profiling float salinities in highly variable environments. Deep. Sea Res. Part II Top. Stud. Oceanogr. 2005, 52, 651-664. [CrossRef]

31. Owens, W.B.; Wong, A.P. An improved calibration method for the drift of the conductivity sensor on autonomous CTD profiling floats by $\theta-S$ climatology. Deep. Sea Res. Part I Oceanogr. Res. Pap. 2009, 56, 450-457. [CrossRef]

32. Notarstefano, G.; Poulain, P.-M. Delayed Mode Quality Control of Argo Salinity Data in the Mediterranean Sea A Regional Approach; Istituto Nazionale di Oceanografia e di Geofisica Sperimentale: Trieste, Italy, 2012; p. 19. 
33. Cabanes, C.; Thierry, V.; Lagadec, C. Improvement of bias detection in Argo float conductivity sensors and its application in the North Atlantic. Deep. Sea Res. Part I Oceanogr. Res. Pap. 2016, 114, 128-136. [CrossRef]

34. Rio, M.H.; Pascual, A.; Poulain, P.-M.; Menna, M.; Barceló-Llull, B.; Tintoré, J. Computation of a new mean dynamic topography for the Mediterranean Sea from model outputs, altimeter measurements and oceanographic in situ data. Ocean Sci. 2014, 10, 731-744. [CrossRef]

35. Nardelli, B.B. A multi-year time series of observation-based 3D horizontal and vertical quasi-geostrophic global ocean currents. Earth Syst. Sci. Data 2020, 12, 1711-1723. [CrossRef]

36. Guinehut, S.; Dhomps, A.-L.; Larnicol, G.; Le Traon, P.-Y. High resolution 3-D temperature and salinity fields derived from in situ and satellite observations. Ocean Sci. 2012, 8, 845-857. [CrossRef]

37. Mulet, S.; Rio, M.-H.; Mignot, A.; Guinehut, S.; Morrow, R. A new estimate of the global 3D geostrophic ocean circulation based on satellite data and in-situ measurements. Deep. Sea Res. Part II Top. Stud. Oceanogr. 2012, 77-80, 70-81. [CrossRef]

38. Molinari, R.; Kirwan, A.D. Calculations of Differential Kinematic Properties from Lagrangian Observations in the Western Caribbean Sea. J. Phys. Oceanogr. 1975, 5, 483-491. [CrossRef]

39. Essink, S.; Hormann, V.; Centurioni, L.R.; Mahadevan, A. Can We Detect Submesoscale Motions in Drifter Pair Dispersion? J. Phys. Oceanogr. 2019, 49, 2237-2254. [CrossRef]

40. Tarry, D.R.; Essink, S.; Pascual, A.; Ruiz, S.; Poulain, P.; Özgökmen, T.; Centurioni, L.R.; Farrar, J.T.; Shcherbina, A.; Mahadevan, A.; et al. Frontal Convergence and Vertical Velocity Measured by Drifters in the Alboran Sea. J. Geophys. Res. Oceans 2021, 126. [CrossRef]

41. Choi, J.; Bracco, A.; Barkan, R.; Shchepetkin, A.F.; McWilliams, J.C.; Molemaker, J.M. Submesoscale Dynamics in the Northern Gulf of Mexico. Part III: Lagrangian Implications. J. Phys. Oceanogr. 2017, 47, 2361-2376. [CrossRef]

42. Cushman-Roisin, B.; Heil, W.H.; Nof, D. Oscillations and rotations of elliptical warm-core rings. J. Geophys. Res. Space Phys. 1985, 90, 11756. [CrossRef]

43. Buongiorno Nardelli, B.; Santoleri, R.; Sparnocchia, S. Small mesoscale features at a meandering upper-ocean fron in the western Ionian Sea (Mediterranean Sea): Vertical motion and potential vorticity analysis. J. Phys. Oceanogr. 2001, 31, $227-2250$.

44. Barceló-Llull, B.; Pallàs-Sanz, E.; Sangrà, P.; Martínez-Marrero, A.; Estrada-Allis, S.; Arístegui, J. Ageostrophic Secondary Circulation in a Subtropical Intrathermocline Eddy. J. Phys. Oceanogr. 2017, 47, 1107-1123. [CrossRef]

45. Pascual, A.; Gomis, D.; Haney, R.L.; Ruiz, S. A quasigeostrophic analysis of a meander in the Palamos Canyon: Vertical velocity, peopotential tendency and relocation technique. J. Phys. Oceanogr. 2004, 34, 2274-2287. [CrossRef]

46. Lilly, J.M.; Gascard, J.-C. Wavelet ridge diagnosis of time-varying elliptical signals with application to an oceanic eddy. Nonlinear Process. Geophys. 2006, 13, 467-483. [CrossRef]

47. Lilly, J.M.; Pérez-Brunius, P. Extracting statistically significant eddy signals from large Lagrangian datasets using wavelet ridge analysis, with application to the Gulf of Mexico. Nonlinear Process. Geophys. 2021, 28, 181-212. [CrossRef] 